\title{
Marine Air Penetration in California's Central Valley: Meteorological Drivers and the Impact of Climate Change ${ }^{\mathscr{O}}$
}

\author{
Meina Wang AND Paul UllRich \\ University of California, Davis, Davis, California
}

(Manuscript received 4 April 2017, in final form 23 August 2017)

\begin{abstract}
This study focuses on one of the most common coastal phenomena within California's San Francisco Bay Delta and Central Valley-marine air penetration (MAP) events, which are a broad category of meteorological features that include the well-known "delta breeze." Summertime MAP episodes, identified by an inland cooling pattern and onshore wind, are selected in both observational and reanalysis datasets using a newly developed set of objective criteria. Correlations between MAP occurrence and synoptic-scale meteorological patterns are then examined to understand the drivers of MAP. Historical data are first used to determine whether any significant trends have been observed in the frequency and character of MAP events. Future trends in MAP are then predicted on the basis of an investigation of how synoptic-scale meteorological patterns will be modified in the twenty-first century under CMIP5 climatological projections. From the analysis of historical and future MAP frequency (under RCP8.5), a weak positive trend $\left[\sim 0.2\right.$ days $\left.(100 \mathrm{yr})^{-1}\right]$ is identified in the occurrence of sufficiently strong summertime MAP days, although further study is needed.
\end{abstract}

\section{Introduction}

Unprecedented climate change is expected in the next century, with inevitable and significant impacts anticipated on health, welfare, and economies worldwide. Although the large-scale impacts of climate change are understood well, there remains substantial uncertainty with regard to how it will affect local-scale meteorological conditions, which are of greater relevance for local stakeholders. Since projections of climate change over the coming century are typically only available at resolutions that are insufficient to represent local-scale meteorological features, there is a pressing need for the development of new statistical techniques to connect these unresolved features to well-resolved large-scale and synoptic-scale meteorological patterns (Grotjahn et al. 2016). To this end, this study investigates the development and application of one such technique to a particular coastal phenomenon-marine air penetration (MAP) events (Fosberg and Schroeder 1966; Read 1971;

Supplemental information related to this paper is available at the Journals Online website: https://doi.org/10.1175/ JAMC-D-17-0089.s1.

Corresponding author: Meina Wang, mnawang@ucdavis.edu
Olsson et al. 1973; Hsu 2013). Literature on this topic has widely varying nomenclature for these events, including MAP, marine air intrusion (MAI), marine air invasion, or onshore surge of marine air. These terms essentially all describe the onshore flow component that causes the cool and moist marine air to penetrate far inland. The cooling that comes with the MAP events is the most socially influential impact since it can alter local energy consumption as well as bring cooling relief during summertime to densely populated area such as the "California Delta" region. MAP exemplifies many of the issues associated with projecting climate change at fine spatial scales: the character of MAP events strongly depends on coastal topography but restrictions on model resolution (driven by computational constraints) require topography to be smoothed out, leading to a poor representation of MAP in global models.

The goal of this study is to understand the connections between MAP events of sufficient strength and largescale meteorological patterns and to use that insight to understand potential trends in MAP events in the future. Our approach proceeds as follows: First, a set of objective criteria for identifying MAP events is developed on the basis of available meteorological observations. Next, five synoptic-scale meteorological indicators are identified that are strongly associated with MAP events. Third, 

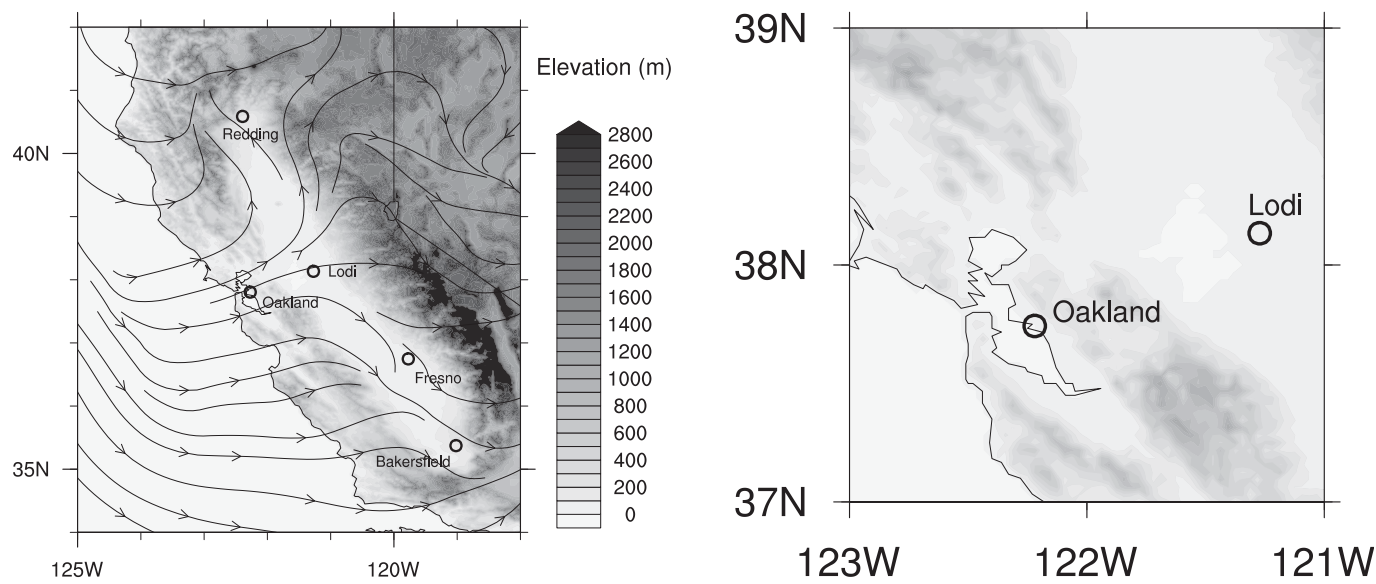

FIG. 1. (left) A topographical map of the San Francisco Bay area and Carquinez Strait showing the position of Oakland and Lodi. (right) A topographical map of California depicting the California Central Valley and the locations of Oakland, Lodi, and Fresno. Wind streamlines for a typical MAP episode (obtained from CFSR data; see section 3) are superimposed.

these indicators are applied to historical reanalysis and future projections from phase 5 of the Coupled Model Intercomparison Project (CMIP5) to identify any trend in MAP frequency.

The remainder of this paper is as follows. First, the character and impacts of MAP events in California are described in section 2. Section 3 outlines the datasets that have been used in this analysis, and section 4 describes our criteria for objective detection of MAP days. Using these criteria for MAP occurrence, section 5 then describes the anomalous large-scale meteorological fields that we have found to be associated with MAP events. These fields are then used in section 6 to identify five objective indicators that are associated with MAP occurrence, and a statistical model is developed for predicting MAP days on the basis of these indicators. This statistical model is then applied in section 7 to understand how MAP frequency may be changing in response to a warming climate. Discussion and conclusions follow in section 8 .

\section{Marine air penetration}

MAP events occur in many near-coastal locations throughout the world, driven by rough coastal topography that blocks marine air from penetrating inland everywhere except through one or more narrow regions. In this study, we focus specifically on MAP events that occur in the California San Francisco Bay Delta and Central Valley regions (see Fig. 1). In this context, MAP is a general meteorological feature composed of both mesoscale and synoptic-scale phenomena: the daily seabreeze circulation, which naturally arises in response to a land-ocean temperature contrast as a product of a differing heat capacity of the land versus the ocean (Read 1971; Miller et al. 2003), and the Pacific Coast monsoon (Read 1971), which is a slow and steady transport of marine air inland from the North Pacific Ocean anticyclone (Schroeder et al. 1967). This latter component enhances the onshore sea-breeze flow and allows for marine air to penetrate farther inland than the sea breeze would normally allow. Note that MAP should not be considered interchangeably with the well-known "California Delta Breeze," which must be associated with a sea-breeze front (Bellinder 2012; Mayor 2011).

MAP events in California most often occur from the late-spring through early-autumn months and usually peak in intensity and frequency in the summertime, when the temperature and pressure gradients are the greatest between land and ocean (Schroeder et al. 1967). The coastal topography of California is necessary for MAP events and acts as a mesoscale "amplifier" that can influence the synoptic-scale "signal" (Mass et al. 1986). Further, during summertime, MAP events can be intensified by the California Delta Breeze as the latter is superimposed on the monsoon flow (Fosberg and Schroeder 1966).

MAP episodes are a dominant feature of summertime weather in California's near-delta Central Valley. A MAP event can be a relief from summertime heat by transporting cool moist marine air inland, which can alter local temperature and decrease health risks due to prolonged heat exposure. In turn, a MAP event can drive down electricity demand, which is typically dominated by indoor environmental conditioning during summer months (Davis et al. 2005), or can alter local air 
quality via inland ventilation (Beaver and Palazoglu 2006; Simpson 1994). MAP events exist along a spectrum, ranging from weak MAP episodes that rarely carry marine air beyond the San Francisco Bay Delta through strong events that effectively ventilate a large fraction of the California Central Valley. The strongest MAP events, and the ones that are the focus of this study, are associated with the combination of a sea breeze and a large-scale flow pattern that enhances the wind field. These events are of particular interest, because it is events of this nature that have the potential to counteract climate change-induced warming in the Central Valley.

Past studies of MAP have typically used observational datasets to identify individual events (Fosberg and Schroeder 1966; Olsson et al. 1973; Mass et al. 1986). A study by Zaremba and Carroll (1999) analyzed the more general summer wind-flow regimes over the Sacramento Valley in 1991. They classified the wind regime by observing the wind direction in Davis, California, which sits just north of the San Francisco Bay Delta. Over their study period (May-September 1991), 72\% of the days were classified as having some of the features of marine air intrusion (southerly wind at Davis).

Sources that have analyzed projected temperature and wind fields suggest that stronger sea-breeze events will occur in coastal California in response to climate change (Lebassi et al. 2009). It is unclear if their assessment, which is motivated by a projected increase in land-ocean temperature contrast, is applicable to MAP, which is more strongly connected with synoptic-scale meteorological fields (Fosberg and Schroeder 1966). Therefore, our study aims to understand whether a similar trend is also anticipated for MAP events.

\section{Datasets}

This study uses a number of datasets for the purposes of identifying MAP events. For understanding the local character of MAP events, observational data from California Irrigation Management Information System (CIMIS) stations (Snyder 1984) (http://www.cimis. water.ca.gov/) and radiosonde observation data from the Oakland, California, airport (OAK; station number 72493) (University of Wyoming Department of Atmospheric Science; http://weather.uwyo.edu/ upperair/sounding.html) were used. The CIMIS data are hourly observations, and the sounding data are 12-hourly; only the afternoon hours were used for both datasets. For understanding the large-scale meteorological patterns associated with MAP events, the National Centers for Environmental Prediction (NCEP)
Climate Forecast System Reanalysis (CFSR) is used (Saha et al. 2010). Among the available CFSR datasets, we chose its analysis subset, which provides $0.5^{\circ}$ spatial resolution with output every $6 \mathrm{~h}$ between 1979 and 2010 . For understanding future trends in MAP frequency, we use data from the twenty-first-century from CMIP5 (Taylor et al. 2012) and twenty-first-century AMIP-style simulations produced using the Variable Resolution Community Earth System Model (VR-CESM) (Huang et al. 2016; Rhoades et al. 2016).

The five CMIP5 datasets that we used are given in Table 1 along with their nominal grid resolution. This selection of datasets represents relatively even coverage from research groups around the world.

\section{A set of objective criteria for MAP events}

Since MAP events are not a binary phenomenon, no singular objective criterion is available for the identification of these features. That is, MAP events are a general feature that includes any instance of a "sufficiently strong" onshore wind capable of pushing marine air into the Central Valley. Among the summer windflow regimes in California, as categorized by Zaremba and Carroll (1999, hereinafter ZC), we are interested in events of categories I-III, which are associated with onshore flow through the San Francisco Bay Delta. These wind regimes, when compared with the mean summertime climate, are associated with a local onshore wind of particular strength in the late afternoon, cooler inland temperatures, and higher specific humidity. Figure 1 shows a map of this region, along with the typical path of MAP winds.

In developing an objective criterion for MAP events, it is important to consider any potential issues that may arise as a result of the observed fields, such as observational uncertainty and signal-to-noise ratio. With this in mind, a set of criteria is proposed that utilizes temperature and wind direction: First, a MAP event must drive a localized cooling through the San Francisco Bay Delta, which we identify from a sufficiently large surface temperature difference between an inland location in the south of the Central Valley that is mostly insulated from onshore flows (Fresno; $36.8^{\circ} \mathrm{N}, 119.7^{\circ} \mathrm{W}$ ) and the eastern tip of the San Francisco Bay Delta (Lodi; $38.1^{\circ} \mathrm{N}$, $\left.121.4^{\circ} \mathrm{W}\right)$. These locations are also chosen, in part, because of the fidelity of the CIMIS temperature measurements at each location. Here, the spatial temperature difference is advantageous since it effectively removes the historical climate change signal (no observable trend was found in the temperature difference from CIMIS observations over the 1980-2010 period) and only triggers for events that deliver a sufficiently 
TABLE 1. Selected CMIP5 models for assessing future trends in MAP days.

\begin{tabular}{lcl}
\hline \hline Model name & Grid resolution $($ lat $\times$ lon $)$ & \multicolumn{1}{c}{ Institution } \\
\hline CCSM4 & $0.9424^{\circ} \times 1.25^{\circ}$ & National Center for Atmospheric Research, United States \\
EC-EARTH & $1.1215^{\circ} \times 1.125^{\circ}$ & EC-EARTH consortium, European Centre \\
MRI-CGCM3 & $1.12148^{\circ} \times 1.125^{\circ}$ & Meteorological Research Institute, Japan \\
HadGEM2-ES & $1.25^{\circ} \times 1.875^{\circ}$ & Met Office Hadley Centre, United Kingdom \\
MPI-ESM-MR & $1.8653^{\circ} \times 1.875^{\circ}$ & Max Planck Institute for Meteorology, Germany \\
\hline
\end{tabular}

strong cooling along the San Francisco Bay. Second, a MAP event must be associated with an onshore wind at the Oakland radiosonde. To develop these criteria, local wind direction at $900 \mathrm{hPa}$ was assessed using both radiosonde measurements from Oakland at 0000 UTC (1700 local time) and inland meteorological station measurements. Of these two, the Oakland radiosonde was found to be the most reliable indicator of a MAPlike wind regime (i.e., ZC categories I-III), because inland and near-surface wind observations exhibited more noise from local surface effects. A criterion for the specific humidity field at Lodi was also considered but was found to be poorly indicative of strong onshore flow through the delta and ventilation of the Central Valley. The weak signal was likely due to the cooler temperatures and relatively low specific humidity of the North Pacific.

The strength of the temperature and wind criteria has been tuned to provide a representative sample of sufficiently strong MAP events while avoiding false positives that were clearly not associated with a MAPlike wind regime and weak also avoiding MAP days that are associated with the diurnal sea breeze but not with a large-scale meteorological forcing. In specific terms, the temperature criterion was chosen to equal the mean temperature difference between Fresno and Lodi minus 1 standard deviation. Consequently, the proposed observational MAP criteria are the following:

1) The surface temperature difference between Fresno and Lodi must be greater than or equal to $7^{\circ} \mathrm{C}$.

2) The $900-\mathrm{hPa}$ across-shore wind speed must be greater than or equal to $3 \mathrm{~m} \mathrm{~s}^{-1}$. The across-shore direction is defined as perpendicular to the West Coast shoreline at $150^{\circ}$ southeast, and positive across-shore wind speed indicates onshore wind.

Here the $7^{\circ} \mathrm{C}$ difference was selected by first calculating the mean temperature difference between Fresno and Lodi $\left(9.0^{\circ} \mathrm{C}\right)$, minus 1 standard deviation $\left(2.1^{\circ} \mathrm{C}\right)$. Our motivation was to include the stronger cooling days (at Lodi) while eliminating the weaker ones and then to further select the MAP events using the onshore wind criterion. These two criteria added together allow us to select the onshore flow with sufficient cooling effect around the delta region. The onshore wind direction was defined as wind direction ranging from $150^{\circ}$ to $330^{\circ}$, as an approximation of onshore direction with respect to the U.S. western coastline. The across-shore wind speed was then defined as the wind component from the onshore wind that was perpendicular to the coastline. From the wind direction histogram (not shown), the onshore wind was found to be the most frequent.

As discussed earlier, MAP events exist along a spectrum and so there remains some latitude in defining thresholds to ensure that only the most significant events are captured. The thresholds chosen above allow us to eliminate the weakest MAP events while also maintaining a sufficient statistical sample of these events. Simply using the two observational MAP criteria above, we were able to detect a lower surface temperature, higher surface water vapor mixing ratio, and higher surface wind speed during the afternoon hours on MAP days (blue lines in Fig. 2) relative to non-MAP day (black lines in Fig. 2) from hourly CIMIS data. Surface temperature at Fresno (dashed lines in Fig. 2) did not show much influence under MAP days because Fresno is located farther from the delta region.

CFSR data from 2001 to 2010 were initially used in this study to assess the performance of the observational criteria. The number of MAP days that match the criteria for each month over the 10 -yr period is plotted in Fig. 3. Consistent with the known climatological characteristics of MAP events (Fosberg and Schroeder 1966), most MAP days occurred during the summer months [June-August (JJA)]. In our analysis, approximately $46 \%$ of all JJA days over the $2001-10$ period are classified as MAP days. Although this is many fewer than the $72 \%$ of summer days identified as MAI days by Zaremba and Carroll (1999), this difference again represents our freedom to isolate only MAP days of sufficient strength.

Because this study requires the large-scale climatological fields associated with MAP days, the CFSR reanalysis dataset was adopted. Although CFSR is closely constrained to meteorological station data in this region, there are slight differences in the mean climatological 
Temperature (C)
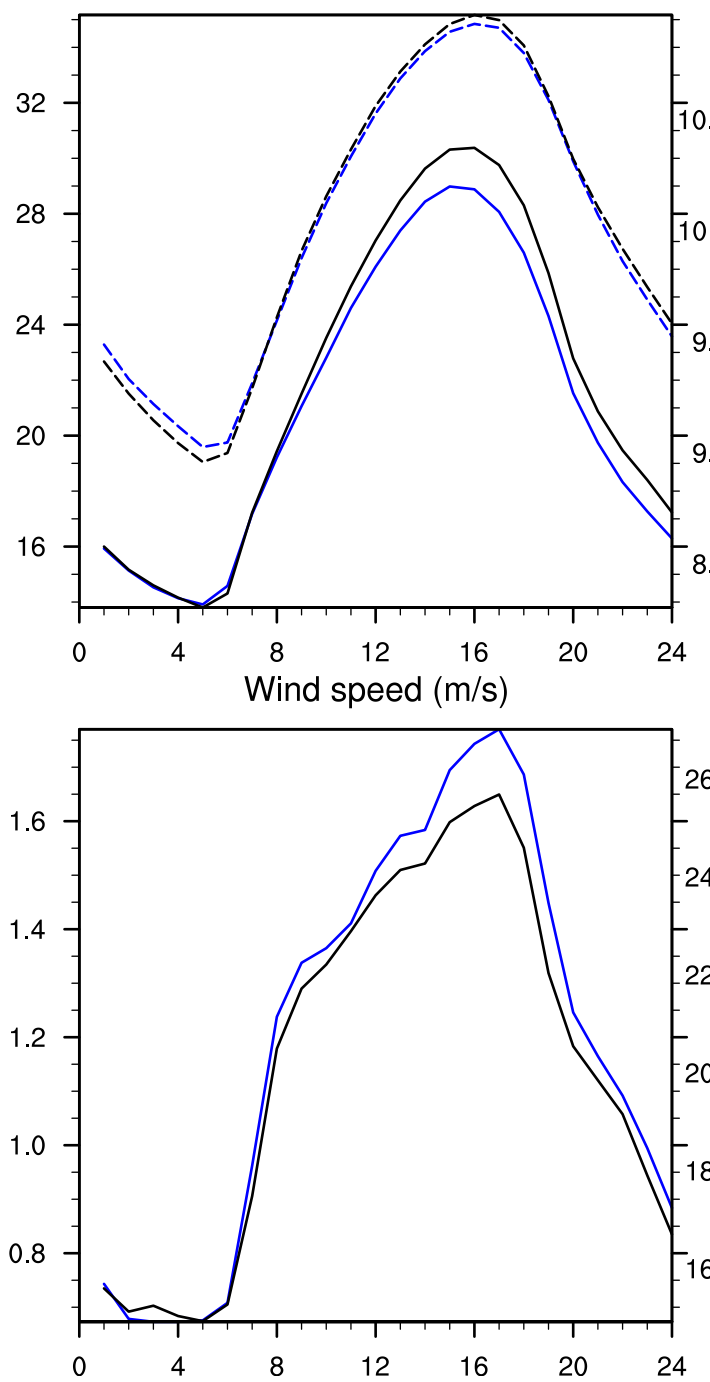

Water vapor mixing ratio $(\mathrm{g} / \mathrm{kg})$

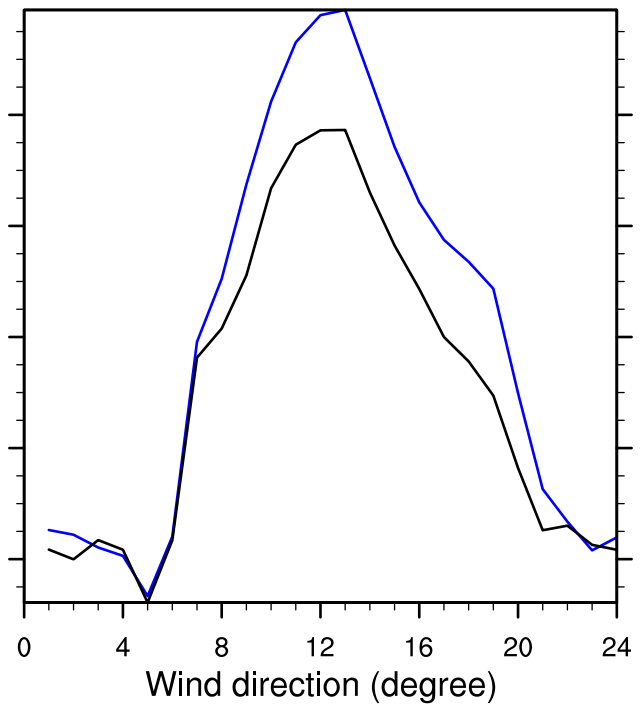

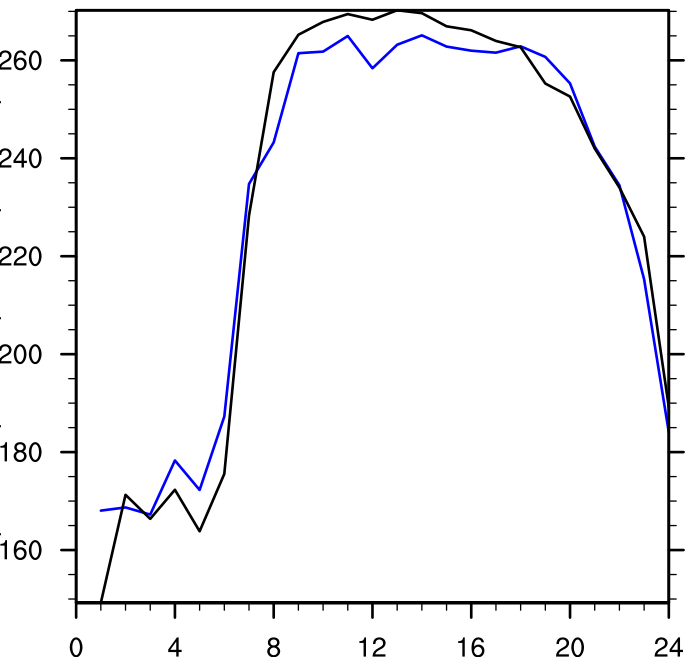

FIG. 2. Hourly mean values of surface temperature, water vapor mixing ratio, wind speed, and wind direction at Lodi (solid lines) on days meeting the observational MAP criteria (blue) and days not meeting the criteria (black) from CIMIS observation. The dashed lines in the top-left panel are surface temperature at Fresno on MAP days (blue) and non-MAP days (black).

characteristics of CFSR and CIMIS that needed to be addressed. Grid points in CFSR are not coincident with meteorological stations, and so the grid point data at $38^{\circ} \mathrm{N}, 121.5^{\circ} \mathrm{W}$ were used for "Lodi" and data at $36.5^{\circ} \mathrm{N}$, $120^{\circ} \mathrm{W}$ were used for "Fresno." As a consequence, the mean temperature difference from CIMIS was observed to be $9.0^{\circ}$ and $10.1^{\circ} \mathrm{C}$ from CFSR. Further, CFSR exhibited a $1.7^{\circ} \mathrm{C}$ trend over the 30 -yr period of 1980 2010 that was not present in CIMIS data, and there was no trend in the temperature difference between Fresno and Lodi from CIMIS data. Last, mean 900-hPa wind speed at Oakland was measured as $3.1 \mathrm{~m} \mathrm{~s}^{-1}$ in CIMIS and $3.8 \mathrm{~m} \mathrm{~s}^{-1}$ in CFSR. Consequently, our thresholds for
MAP events have been adjusted to account for the best match between the CFSR and CIMIS data. This led to the CFSR criteria for MAP days, as follows:

1) The surface temperature difference between Fresno and Lodi must be greater than or equal to $8^{\circ} \mathrm{C}+$ $1.7^{\circ} \mathrm{C} \times[(\langle$ YEAR $\rangle-2005) / 30]$.

2) The $900-\mathrm{hPa}$ across-shore wind speed must be greater or equal to $1.87 \mathrm{~m} \mathrm{~s}^{-1}$.

Using these adjusted criteria, the percentage of JJA MAP days in CFSR is found to be approximately $51 \%$ between 2001 and 2010 (the range of YEAR), with a $73 \%$ overlap between the CIMIS and CFSR datasets. 


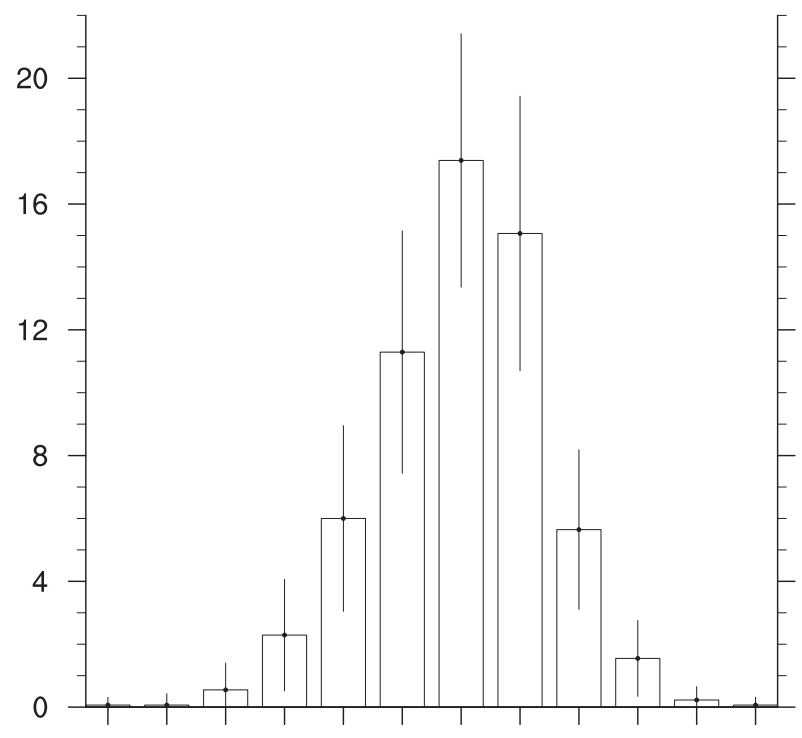

Jan Feb Mar Apr May Jun Jul Aug Sept Oct Nov Dec

FIG. 3. Average number of MAP days per month selected from CIMIS observation between 2001 and 2010. The vertical bars give the standard deviations.

Expanding our study period to 1979-2010 leads to a selection of approximately $47 \%$ of MAP days in CFSR, with a $69 \%$ overlap with CIMIS. Surface temperature, specific humidity, and wind speed fields from the two sets of MAP events plotted in CFSR appear to be very similar.

\section{Synoptic-scale meteorological patterns during MAP events}

For MAP days selected using the CFSR criteria, synoptic- and large-scale meteorological fields describing the $700-\mathrm{hPa}$ geopotential height anomaly, 700-hPa geopotential height, wind anomaly streamlines, wind streamlines, temperature anomalies, and specific humidity anomalies are plotted in Fig. 4. On MAP days, the mean synoptic-scale meteorological pattern is dominated by a high pressure ridge in the Gulf of Alaska accompanied by a coastal trough through the Pacific Northwest. The presence of this trough is effective at modifying the contours of the $700-\mathrm{hPa}$ geostrophic height field (Fig. 4b) to be approximately perpendicular to the coast, which in turn leads to a 700-hPa geostrophic wind directed into the San Francisco Bay Delta. The coastal trough also leads to southwesterly winds throughout the western United States that are then responsible for a large positive temperature anomaly that extends throughout this region. Offshore $900-\mathrm{hPa}$ winds, which are typically northerly, are weakened during MAP days and are shifted to be more closely aligned with the coast. In the San Joaquin Valley, 900-hPa winds are observed to diverge away from the delta, with the strongest winds directed northward. The near-surface onshore winds are then responsible for a drop in surface temperatures through the San Francisco Bay area and a corresponding increase in specific humidity as cool, moist oceanic air is forced through the delta.

Days that only satisfied the onshore wind criteria were similarly assessed and were observed to be associated with a geopotential height anomaly that maintained a Rossby-wave pattern that was similar to that in Fig. 4a but that was far less significant. This result is indicative that the temperature criterion is effective at isolating days when the large-scale circulation enhances the onshore flow.

\section{Synoptic-scale meteorological indicators for MAP events}

The meteorological fields (associated with MAP events) that emerge from Fig. 4 suggest that MAP days are associated with several potential large-scale meteorological indicators. For the purposes of this study, we have proposed the following five criteria as potential binary indicators of MAP days (all of the anomalies are daily average values):

1) The first criterion is the existence of a positive $700-\mathrm{hPa}$ geopotential height anomaly within the region bounded by $30^{\circ}-60^{\circ} \mathrm{N}$ and $165^{\circ}-120^{\circ} \mathrm{W}$. As observed in Fig. 4, MAP days are associated with a dipole in the 700-hPa geopotential anomaly field, with a ridge over the Gulf of Alaska and a trough over the Pacific Northwest. Although the position of the dipole is not consistent year to year, the average anomaly in the Gulf of Alaska still tends to be positive during MAP events.

2) The second criterion is a negative $700-\mathrm{hPa}$ geopotential tendency at $44^{\circ} \mathrm{N}, 125^{\circ} \mathrm{W}$ (the point labeled "A" in Fig. 4a). In the days leading up to a MAP event, it is frequently the case that the geopotential height anomaly dipole shifts eastward (the geopotential height anomaly in the 5 days leading up to the MAP event is plotted in Fig. 5), driving a negative geopotential tendency off the Oregon coast (Fig. 6). As predicted by the quasigeostrophic "omega equation," a negative geopotential anomaly is associated with upward motion that is potentially associated with frontal activity.

3) The third criterion is the presence of an inland daily average surface temperature anomaly at $41.5^{\circ} \mathrm{N}$, $115.5^{\circ} \mathrm{W}$ (the point labeled " $\mathrm{B}$ " in Fig. 4e) of greater than $1^{\circ} \mathrm{C}$. As described earlier, and as apparent in Fig. 4, MAP days are associated with a positive inland temperature anomaly related to the southwesterly 

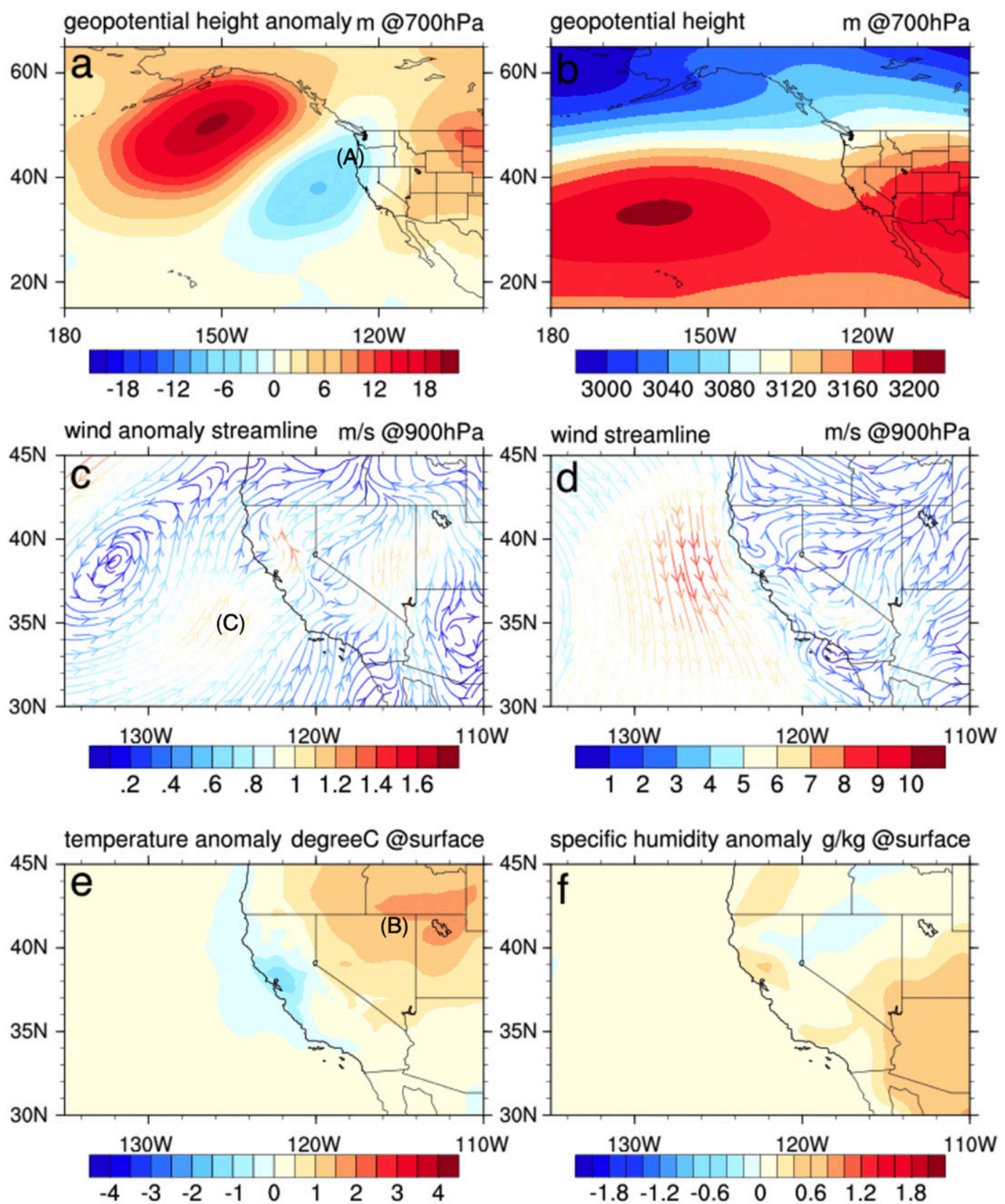

FIG. 4. (b) Geopotential height and (a) height anomaly at $700 \mathrm{hPa}$, (d) wind streamlines and (c) anomaly streamlines at $900 \mathrm{hPa}$, (e) surface temperature anomaly, and (f) surface specific humidity anomaly on CFSR MAP days over the 2001-10 "training" period from CFSR.

wind field. This indicator appears to be maximal in the vicinity of $41.5^{\circ} \mathrm{N}, 115.5^{\circ} \mathrm{W}$.

4) The fourth criterion is an alongshore $700-\mathrm{hPa}$ geopotential height difference between $42^{\circ} \mathrm{N}, 127^{\circ} \mathrm{W}$ and $32.5^{\circ} \mathrm{N}, 121^{\circ} \mathrm{W}$ of less than or equal to $5 \mathrm{~m}$. Geostrophic onshore flow at the $700-\mathrm{hPa}$ level occurs when geopotential contours are perpendicular to the shore-or, equivalent, when there is a geopotential height gradient parallel to the shoreline. In Fig. 4 the presence of geopotential contours perpendicular to the shoreline is indicative that this pattern is prominent during MAP days.

5) An offshore wind speed anomaly at $35^{\circ} \mathrm{N}, 125^{\circ} \mathrm{W}$ (the point labeled " $\mathrm{C}$ " in Fig. 4c) of less than or equal to $2 \mathrm{~m} \mathrm{~s}^{-1}$ is the final criterion. Large offshore wind speeds (particularly northerly winds) tend to lead to 

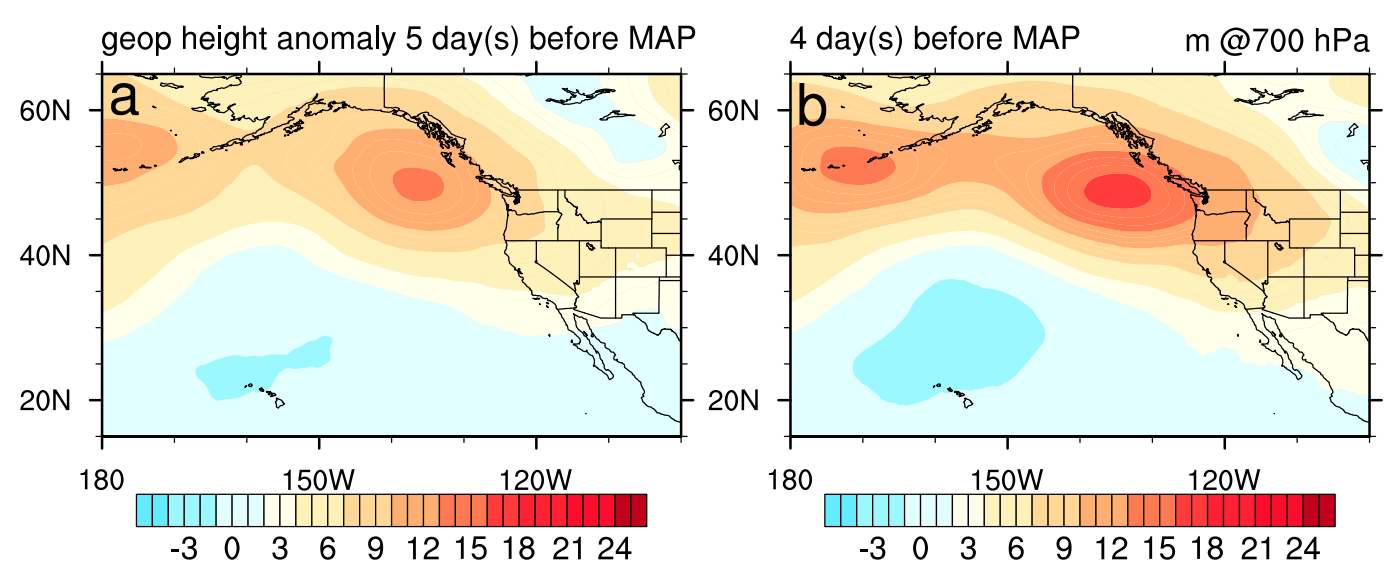

3 day(s) before MAP
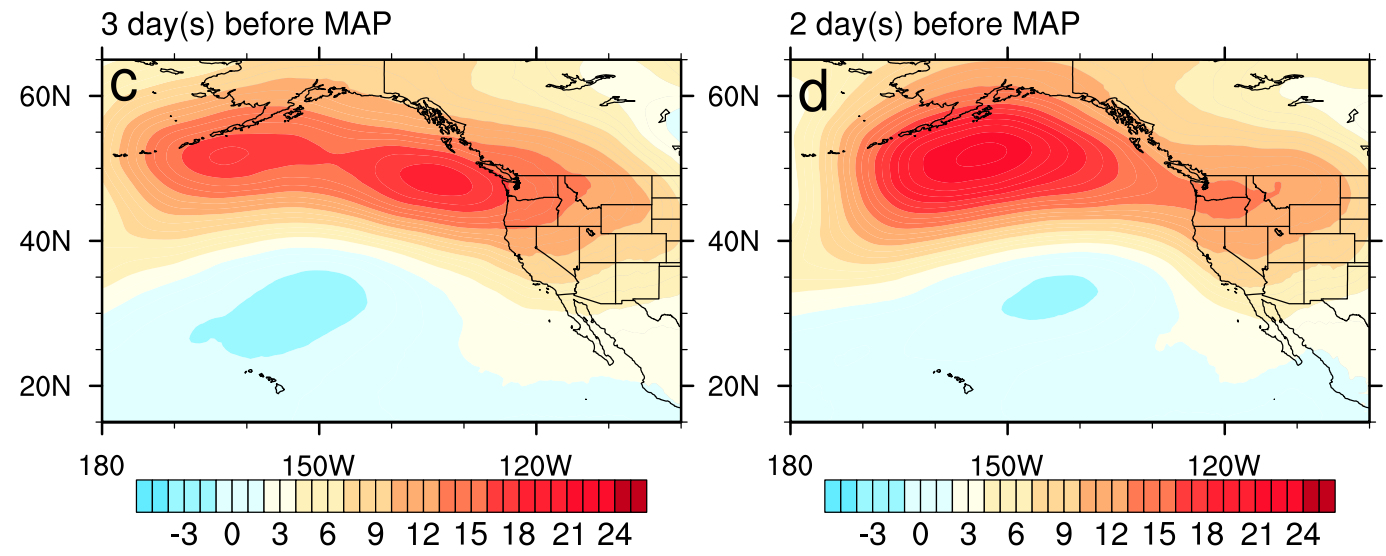

1 day(s) before MAP
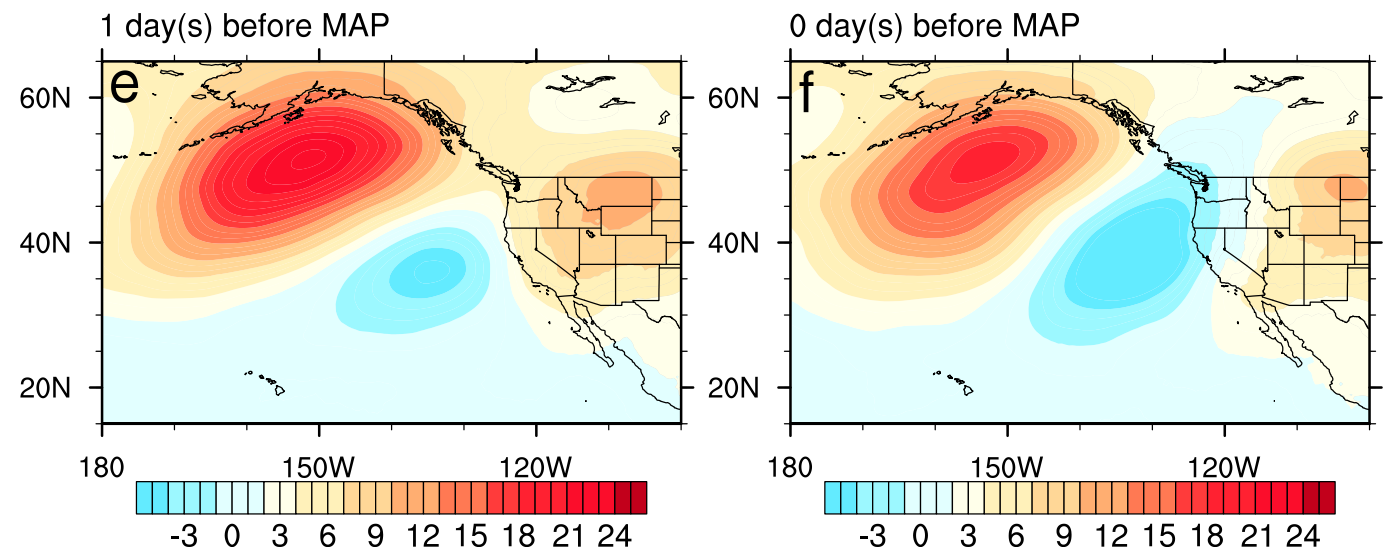

FIG. 5. The 700-hPa geopotential height anomaly field from 5 to 0 days before MAP events from CFSR.

suppressed MAP activity as marine air is pushed along the shore and away from the Bay Delta. On the other hand, MAP days are associated with suppressed offshore wind speeds that can encourage onshore flow. The position $35^{\circ} \mathrm{N}, 125^{\circ} \mathrm{W}$ was chosen because it is at the offshore region where the wind speed anomaly differs most between MAP and non-MAP days.

Using these five indicators, a multivariate logistic regression model was developed. Using the generalized linear model ("glm") from the R software package, it was then determined whether each indicator was a statistically significant indicator of a MAP event. The regression model indicated high significance for all of the five synoptic indicators for 2001-10 (the respective $p$ values for each of the five indicators were $1.22 \times 10^{-11}$, $2 \times 10^{-16}, 1.89 \times 10^{-4}, 2 \times 10^{-16}$, and $9.8 \times 10^{-4}$ ). The strongest indicators for MAP were purely associated with the 700-hPa geopotential field and its corresponding tendency, indicative of the role played by synopticscale meteorology in driving MAP events. The "receiver 

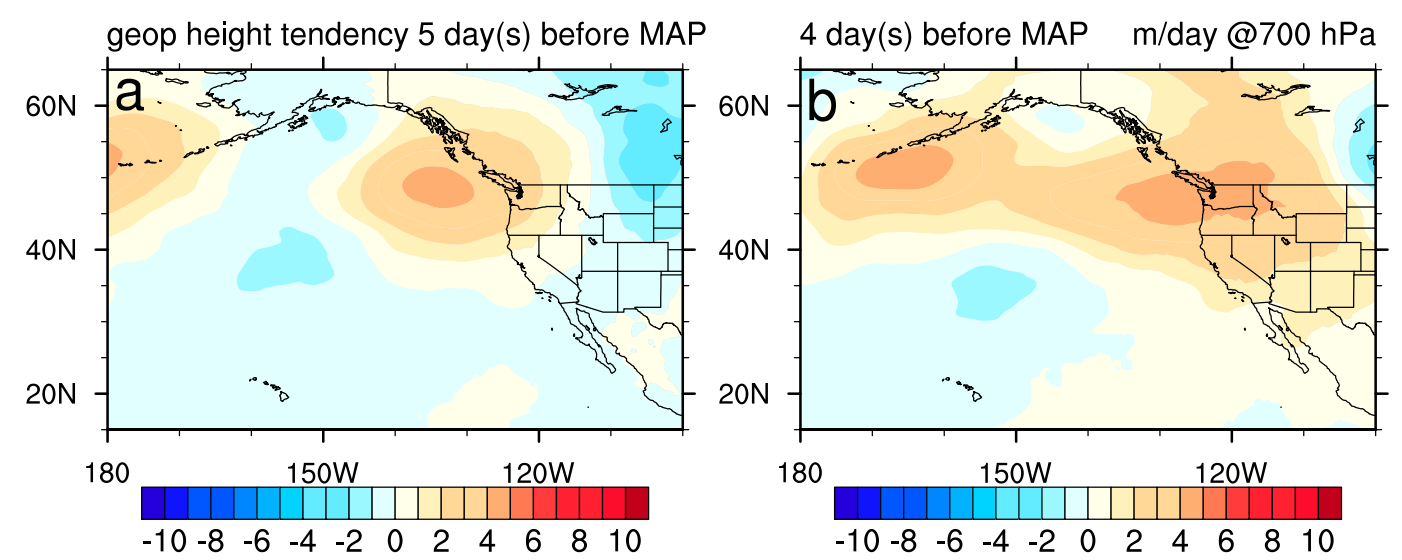

3 day(s) before MAP
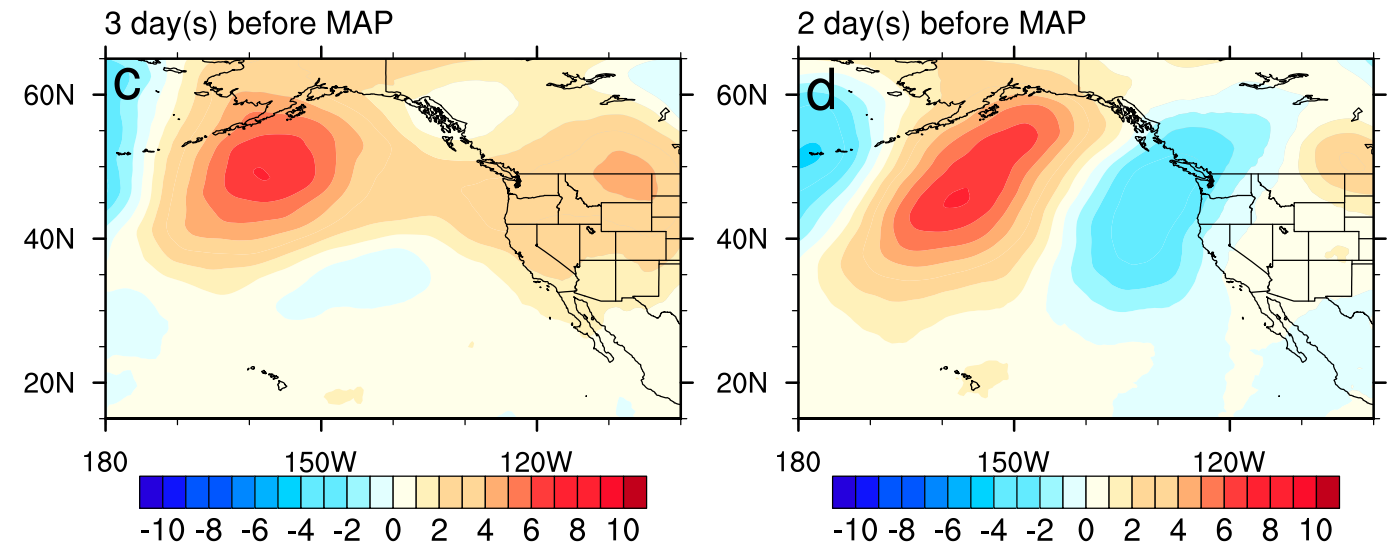

1 day(s) before MAP
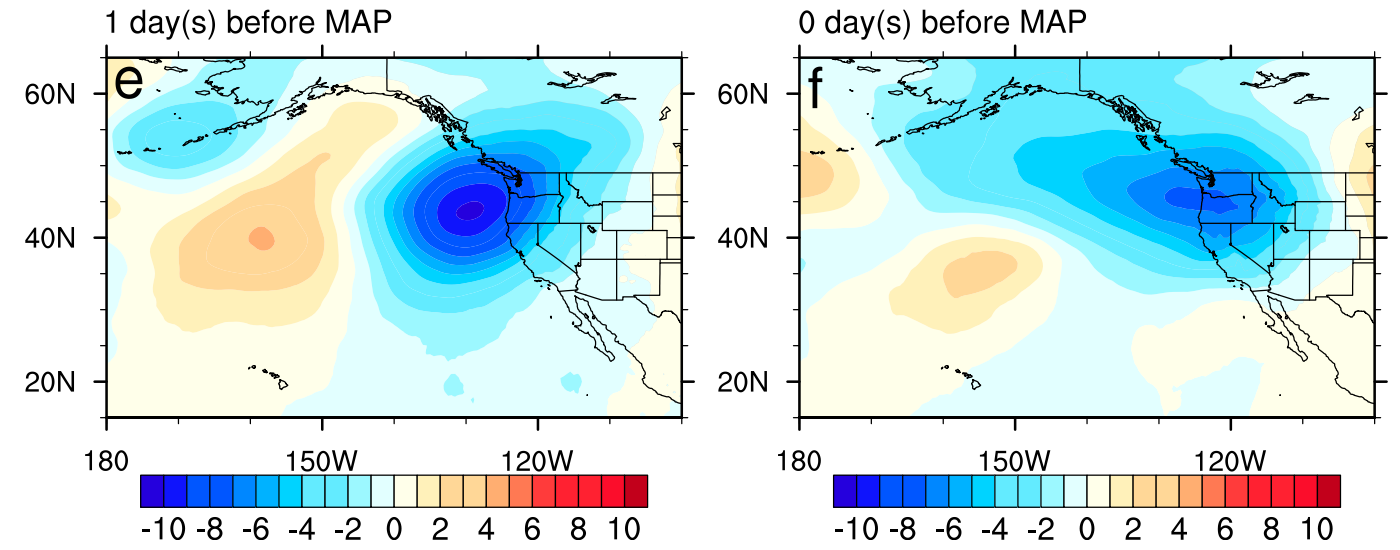

FIG. 6. As in Fig. 5, but for the geopotential tendency field.

operating characteristic" (ROC) curve (see Fig. S1 in the online supplemental material) illustrates the performance of this binary classifier system. The maximum area under curve (AUC) of 1 means a perfect differentiation between MAP and non-MAP, and $\mathrm{AUC}=0.5$ means the classifier is no better than a random guess. For our model, the AUC value was $\sim 0.74$ for $2001-10$. Application of this procedure to 1979-89 and 1990-2000 yielded AUC values of $\sim 0.69$ and $\sim 0.71$, respectively. This result suggests that the model is consistent across all three decades and shows that the large-scale indicators described above will correctly discriminate MAP events from non-MAP events approximately $70 \%$ of the time.

To understand further the relationship between these indicators and the objective MAP criteria, we also assessed the performance of the model as the temperature-difference criterion was varied between $1^{\circ}$ and $12^{\circ} \mathrm{C}$. Indicators 2,3 , and 4 were found to be strongly predictive across all temperatures and so were primarily 
TABLE 2. Number of MAP and non-MAP days in each of the 32 MAP categories for 1979-2010. Categories 2, 4, and 18 (boldface) are the top three most frequent MAP categories, and categories 32 and 16 (boldface) are the top two most frequent non-MAP categories.

\begin{tabular}{|c|c|c|c|c|c|c|c|c|c|c|c|c|c|}
\hline \multirow[b]{2}{*}{ Category } & \multicolumn{5}{|c|}{ Indicators } & \multicolumn{2}{|c|}{ 1979-89 } & \multicolumn{2}{|c|}{ 1990-2000 } & \multicolumn{2}{|c|}{$2001-10$} & \multicolumn{2}{|c|}{ 1979-2010 } \\
\hline & 1 & 2 & 3 & 4 & 5 & MAP & Non-MAP & MAP & Non-MAP & MAP & Non-MAP & MAP & Non-MAP \\
\hline 1 & 1 & 1 & 1 & 1 & 1 & 16 & 3 & 15 & 8 & 15 & 0 & 46 & 11 \\
\hline 2 & 1 & 1 & 1 & 1 & 0 & 69 & 22 & 68 & 26 & 44 & 17 & 181 & 65 \\
\hline 3 & 1 & 1 & 1 & 0 & 1 & 10 & 6 & 3 & 1 & 9 & 5 & 22 & 12 \\
\hline 4 & 1 & 1 & 1 & 0 & 0 & 44 & 30 & 31 & 50 & 60 & 36 & 135 & 116 \\
\hline 5 & 1 & 1 & 0 & 1 & 1 & 3 & 3 & 5 & 2 & 6 & 2 & 14 & 7 \\
\hline 6 & 1 & 1 & 0 & 1 & 0 & 17 & 15 & 14 & 16 & 17 & 7 & 48 & 38 \\
\hline 7 & 1 & 1 & 0 & 0 & 1 & 3 & 3 & 3 & 8 & 4 & 0 & 10 & 11 \\
\hline 8 & 1 & 1 & 0 & 0 & 0 & 18 & 28 & 9 & 31 & 18 & 29 & 45 & 88 \\
\hline 9 & 1 & 0 & 1 & 1 & 1 & 13 & 7 & 6 & 3 & 5 & 2 & 24 & 12 \\
\hline 10 & 1 & 0 & 1 & 1 & 0 & 30 & 13 & 27 & 25 & 28 & 10 & 85 & 48 \\
\hline 11 & 1 & 0 & 1 & 0 & 1 & 6 & 9 & 3 & 7 & 9 & 8 & 18 & 24 \\
\hline 12 & 1 & 0 & 1 & 0 & 0 & 22 & 45 & 23 & 43 & 39 & 28 & 84 & 116 \\
\hline 13 & 1 & 0 & 0 & 1 & 1 & 7 & 5 & 5 & 10 & 5 & 2 & 17 & 17 \\
\hline 14 & 1 & 0 & 0 & 1 & 0 & 11 & 13 & 13 & 18 & 5 & 14 & 29 & 45 \\
\hline 15 & 1 & 0 & 0 & 0 & 1 & 7 & 6 & 3 & 16 & 3 & 10 & 13 & 32 \\
\hline 16 & 1 & 0 & 0 & 0 & 0 & 20 & 64 & 14 & 50 & 18 & 58 & 52 & 172 \\
\hline 17 & 0 & 1 & 1 & 1 & 1 & 4 & 0 & 11 & 3 & 10 & 1 & 25 & 4 \\
\hline 18 & 0 & 1 & 1 & 1 & 0 & 42 & 15 & 41 & 26 & 41 & 15 & 124 & 56 \\
\hline 19 & 0 & 1 & 1 & 0 & 1 & 0 & 1 & 0 & 1 & 1 & 0 & 1 & 2 \\
\hline 20 & 0 & 1 & 1 & 0 & 0 & 11 & 14 & 9 & 17 & 6 & 5 & 26 & 36 \\
\hline 21 & 0 & 1 & 0 & 1 & 1 & 6 & 4 & 3 & 4 & 5 & 4 & 14 & 12 \\
\hline 22 & 0 & 1 & 0 & 1 & 0 & 34 & 35 & 18 & 37 & 34 & 34 & 86 & 106 \\
\hline 23 & 0 & 1 & 0 & 0 & 1 & 2 & 0 & 1 & 4 & 3 & 0 & 6 & 4 \\
\hline 24 & 0 & 1 & 0 & 0 & 0 & 12 & 24 & 4 & 25 & 9 & 22 & 25 & 71 \\
\hline 25 & 0 & 0 & 1 & 1 & 1 & 8 & 2 & 3 & 1 & 6 & 2 & 17 & 5 \\
\hline 26 & 0 & 0 & 1 & 1 & 0 & 20 & 7 & 14 & 14 & 12 & 15 & 46 & 36 \\
\hline 27 & 0 & 0 & 1 & 0 & 1 & 2 & 0 & 1 & 6 & 2 & 1 & 5 & 7 \\
\hline 28 & 0 & 0 & 1 & 0 & 0 & 7 & 21 & 13 & 21 & 7 & 12 & 27 & 54 \\
\hline 29 & 0 & 0 & 0 & 1 & 1 & 4 & 3 & 3 & 7 & 5 & 4 & 12 & 14 \\
\hline 30 & 0 & 0 & 0 & 1 & 0 & 28 & 31 & 14 & 31 & 19 & 35 & 61 & 97 \\
\hline 31 & 0 & 0 & 0 & 0 & 1 & 2 & 7 & 1 & 3 & 0 & 3 & 3 & 13 \\
\hline 32 & 0 & 0 & 0 & 0 & 0 & 7 & 69 & 6 & 92 & 12 & 62 & 25 & 223 \\
\hline
\end{tabular}

associated with the onshore wind criterion. Indicators 1 and 5 were both sensitive to the temperature difference, with maximum predictability attained with a CFSR temperature difference of $8^{\circ} \mathrm{C}$. Other values of the temperature difference led to indicators that either were not significantly correlated or produced a lower AUC value.

Using the five binary indicators (criteria), 32 daily categories are developed on the basis of all possible configurations of indicators, and the resulting classification is given in Table 2. For each of these categories, the numbers of MAP and non-MAP events are given for all JJA days between 1979 and 2010. The configuration of indicators for each category is also given, with 1 indicating that the criterion holds and 0 indicating that it is false. As expected, categories that satisfy a larger fraction of the five indicators also tend to have a larger ratio of MAP to non-MAP days. Days that simultaneously satisfy all five criteria (category 1 ) are fairly rare: although this category includes more than 4 times as many MAP days as non-MAP days, only 46 such days occurred over the 32-yr study period. When categories are weighted by absolute frequency, it is seen that category 2 (which does not trigger indicator 5), category 4 (which does not trigger indicator 4 or 5), and category 18 (which does not trigger indicator 1 or 5) exhibit the greatest occurrence of MAP days.

Figure 7 depicts the synoptic meteorological pattern associated with all days in category 2. It captures 181 MAP days from a total of 1326 MAP days, or $13.7 \%$ of the total number of MAP days between 1979 and 2010. Category-2 days have only a weak offshore wind speed anomaly, but they do feature a large positive geopotential height anomaly (Fig. 7a) that is located in the Gulf of Alaska, accompanied by a weak negative geopotential height anomaly off the Oregon coast. This result suggests a Rossby wave train directed eastward and slightly southward. The negative anomaly acts to redirect 

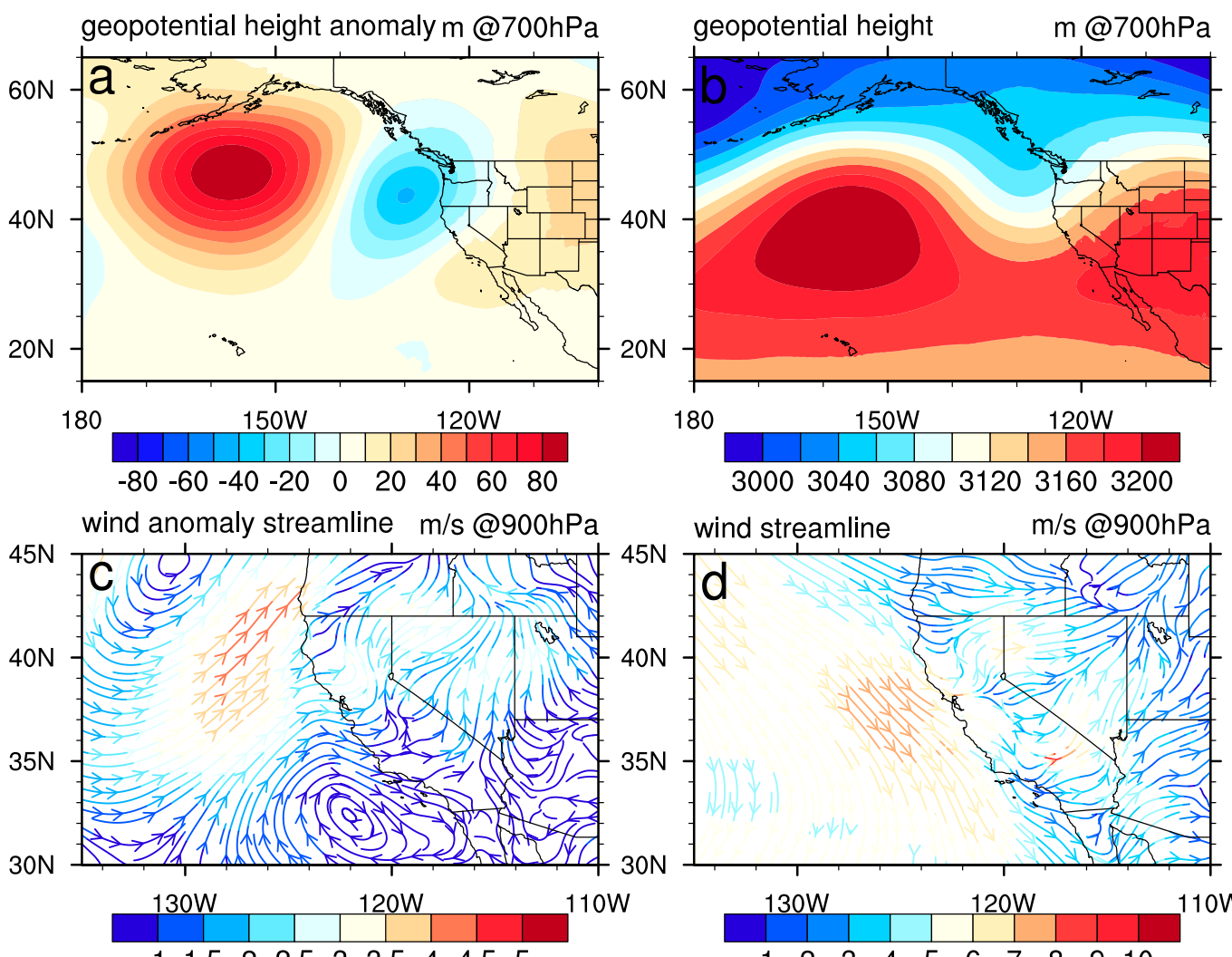

$\begin{array}{lllllllll}1 & 1.5 & 2 & 2.5 & 3 & 3.5 & 4 & 4.5 & 5\end{array}$
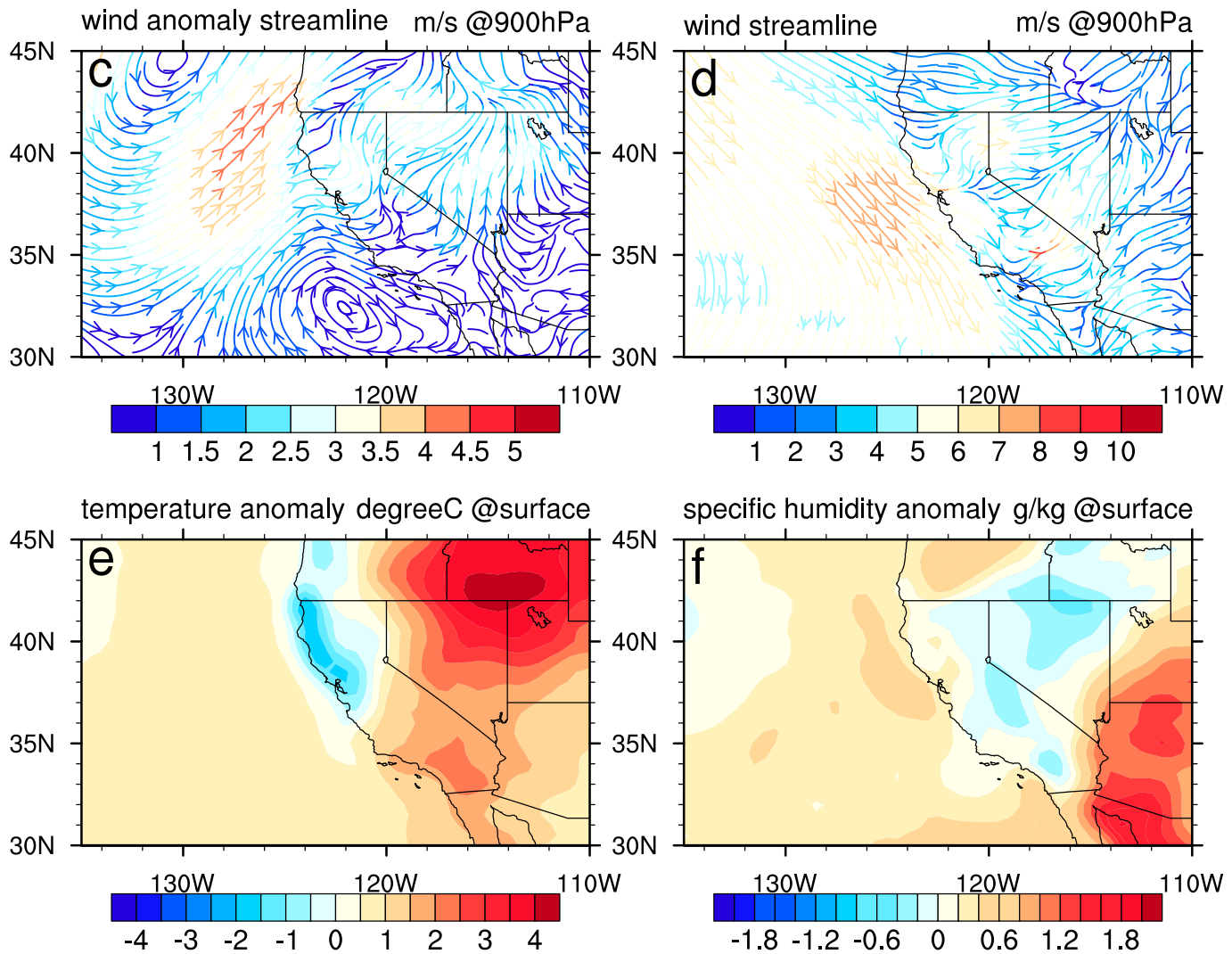

specific humidity anomaly g/kg @surface

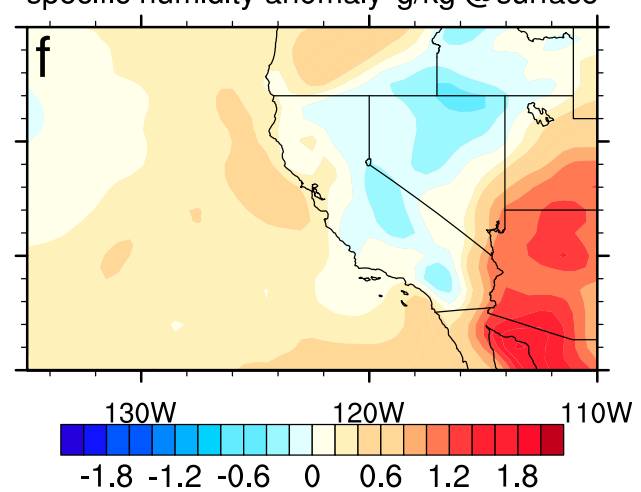

FIG. 7. The synoptic meteorological pattern over the period 1979-2010 for days in category 2 (the most frequent MAP category) from CFSR.

the strong northerly flow off the California coast, leading to onshore winds directed through the San Francisco Bay Delta. The positive specific humidity anomaly (Fig. 7f) extends south along the Baja Peninsula, caused by weakened offshore winds through Southern California.

Figure 8 depicts category 4 , the second-most frequent MAP-event category by total count (135 MAP days, or $10.2 \%$ of total MAP days). This category is similar to category 2 in that it captures days with a positive geopotential anomaly (Fig. 8a) in the North Pacific, but unlike category 2 it is not associated with an offshore trough. Although this configuration is fairly common among summer days, there is only a slightly better than even $(\sim 54 \%)$ chance for this category to produce a MAP event. In this case, the occurrence of MAP will be primarily driven by the local meteorological conditions.

Figure 9 depicts category 18, the third-most frequent MAP-event category, which accounts for 124 MAP days, or $9.4 \%$ of the total number of MAP days. Figure 9a shows a much different large-scale pattern 

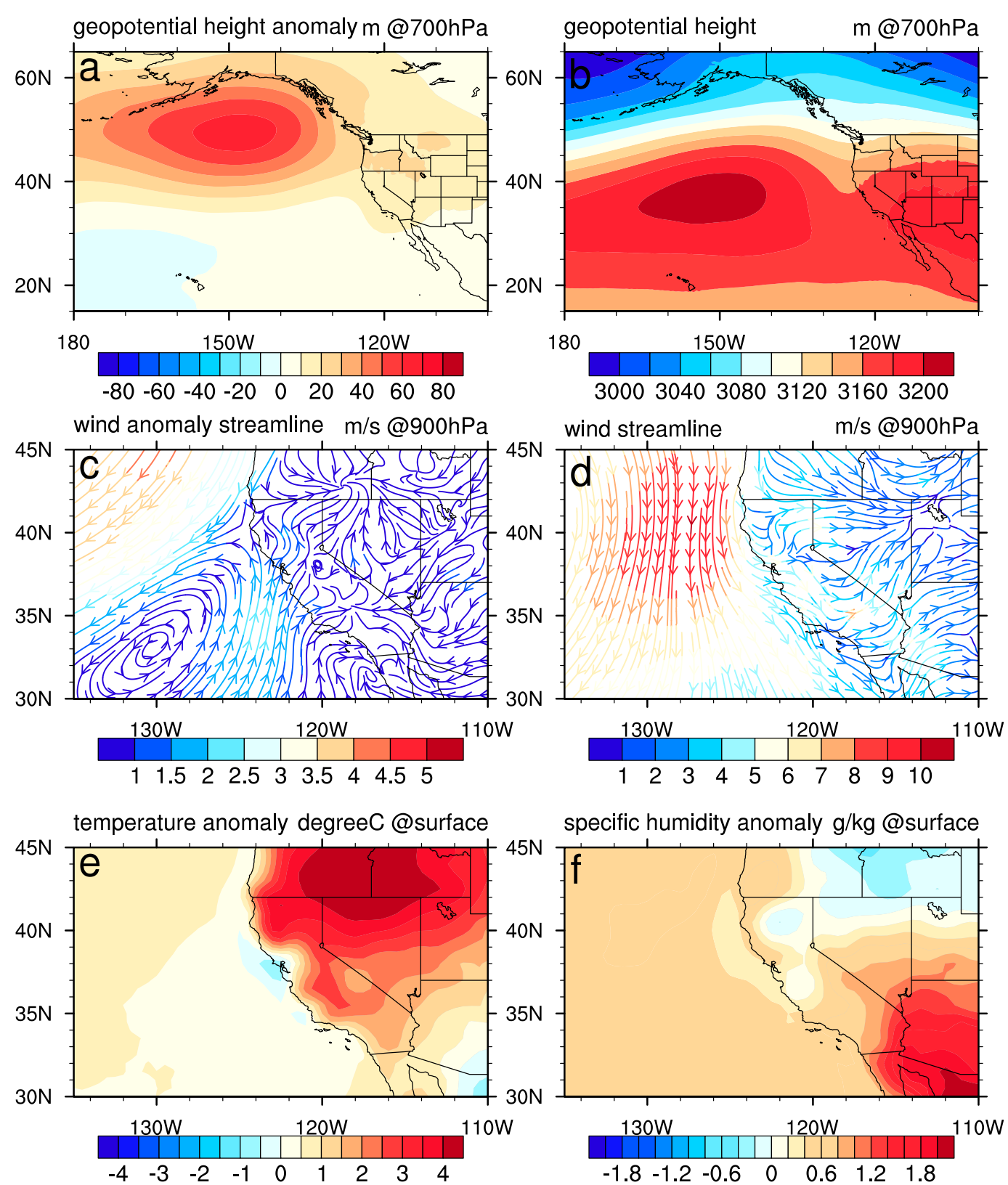

specific humidity anomaly $\mathrm{g} / \mathrm{kg} @$ @surface

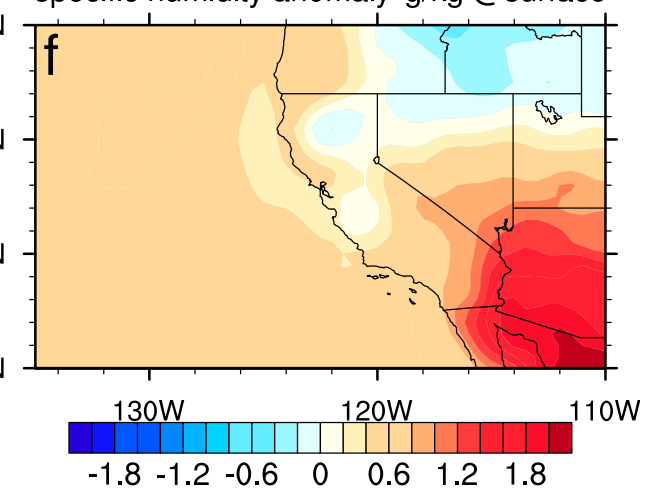

FIG. 8. As in Fig. 7, but for days in category 4 (the second-most frequent MAP category).

when compared with category 2 , particularly in the North Pacific, where there is a strong negative geopotential height anomaly centered at $45^{\circ} \mathrm{N}, 135^{\circ} \mathrm{W}$ that is associated with a Rossby wave train that is inclined to the north. This large negative geopotential height anomaly triggers a substantial weakening of the offshore northerly winds, in turn permitting air to "leak" into the delta. The strength of the geopotential anomaly dipole across the U.S. West also enhances southerly flow in this region and drives a large inland positive temperature anomaly (satisfying criterion 3).
For these three categories, lines of constant negative geopotential height anomaly lie perpendicular to the California coastline, driving the wind anomaly in the onshore direction. Categories 2 and 18 also feature an offshore trough, in agreement with Beaver and Palazoglu (2006). Although it may seem that the offshore trough would be a better indicator of MAP, it turns out that replacing the positive geopotential anomaly indicator 1 with a negative geopotential anomaly indicator off the Oregon coast does not actually improve our ability to detect MAP days. 

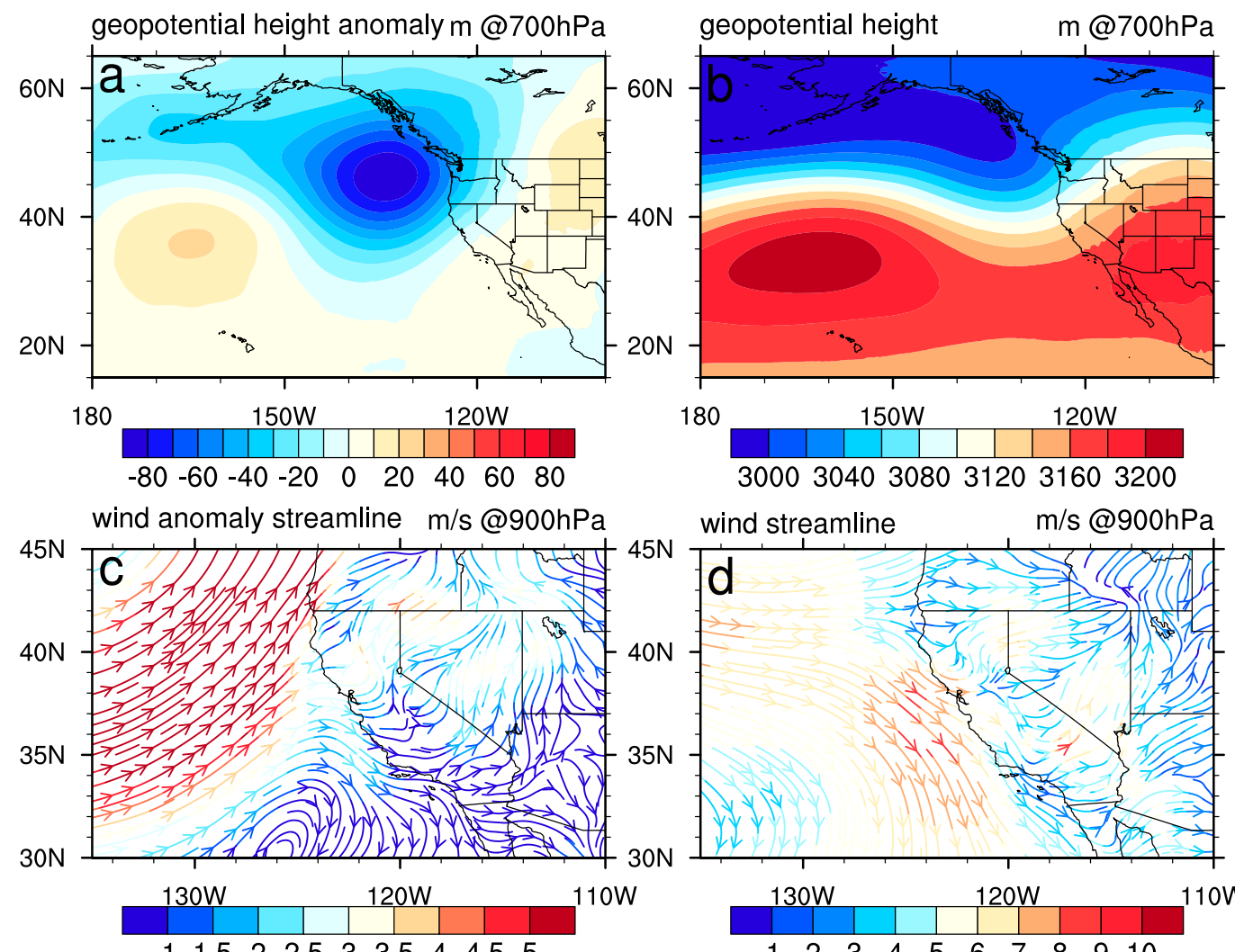

$\begin{array}{lllllllll}1 & 1.5 & 2 & 2.5 & 3 & 3.5 & 4 & 4.5 & 5\end{array}$
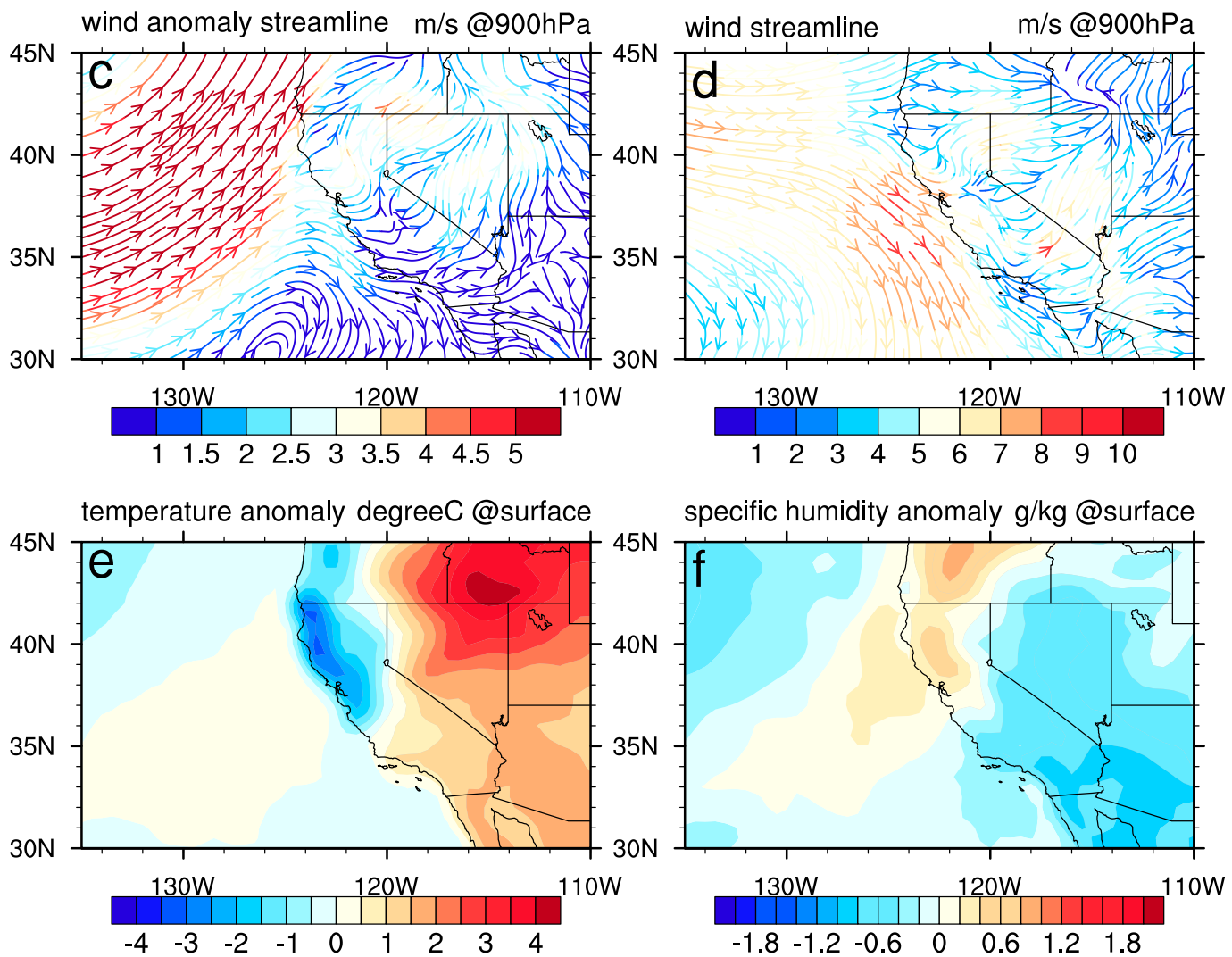

specific humidity anomaly g/kg @surface

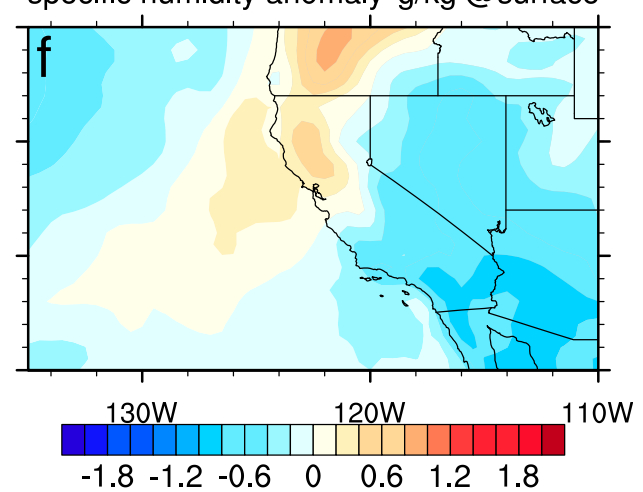

FIG. 9. As in Fig. 7, but for days in category 18 (the third-most frequent MAP category).

In contrast, the most frequent non-MAP events fall into category 32 (depicted in Fig. 10) and account for 223 $(14.4 \%)$ non-MAP days of the 1554 total. In this case, the synoptic-scale pattern (Fig. 10a) is in opposition to the pattern in MAP category 2, with a major negative geopotential height anomaly located in the Gulf of Alaska and a weak positive anomaly located near the Oregon coast. The intensity of the negative geopotential anomaly in this category partially explains why the mean synoptic-scale meteorological pattern indicates a strong positive geopotential anomaly in the North Pacific associated with MAP days (Fig. 4), even though geopotential anomaly in this region takes on opposing signs for the top two MAP categories-namely, a negative geopotential anomaly in this region is frequently associated with a blocking pattern that prevents MAP from occurring.

The second-most frequent non-MAP category is category 16 (Fig. 11), which captures $11.1 \%$ of the nonMAP days and has a dominant positive geopotential height anomaly (Fig. 11a) centered at $45^{\circ} \mathrm{N}, 140^{\circ} \mathrm{W}$. This pattern is again an offshore blocking pattern, here 

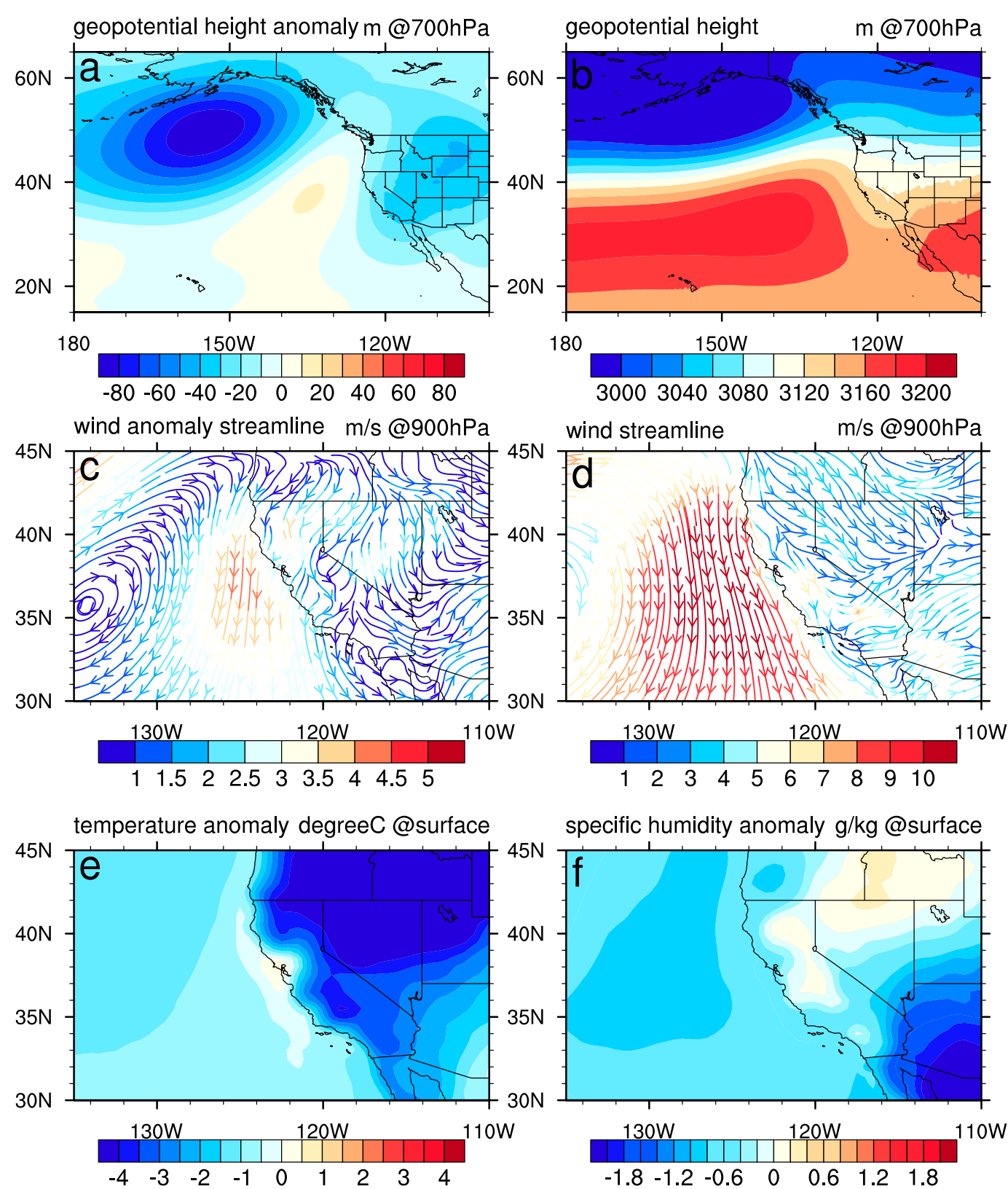

specific humidity anomaly $\mathrm{g} / \mathrm{kg} @$ @urface

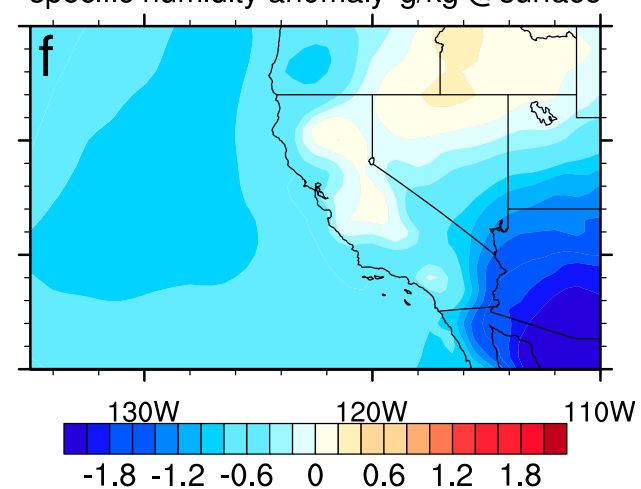

FIG. 10. As in Fig. 7, but for days in category 32 (the most frequent non-MAP category).

exhibiting characteristics in opposition to category 18 (Fig. 9). It is notable that the top two non-MAP categories both have positive geopotential height anomaly contour lines perpendicular to the coastline, enhancing the northerly flow off the California coast and blocking onshore flow.

\section{Future trends in MAP events}

In this section, the categorization strategy from section 6 is used to project future trends in MAP days.
Because MAP events are fairly localized and are driven by quick variations in local topography, they are not actually resolved in the coarse-resolution data that are typically produced by global climate models (GCMs). The indicators identified in section 6 are well resolved, however, even in coarse-resolution GCM data. To estimate the number of MAP days in a given year, the following procedure was performed: For each JJA day over the period 1980-2100, the five binary MAP indicators are computed for each CMIP5 dataset. Cross-referencing the associated category (1- 

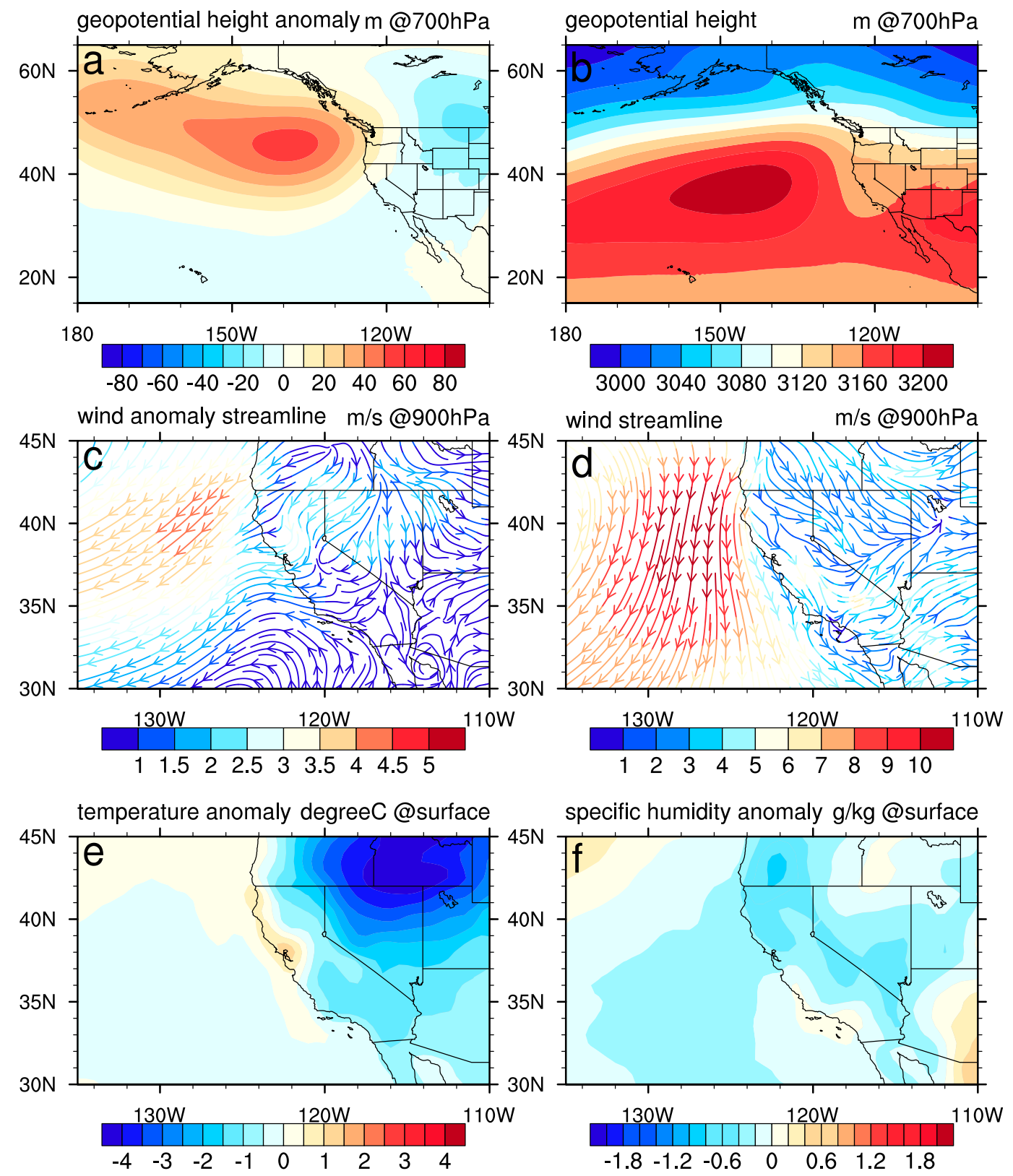

specific humidity anomaly g/kg @surface

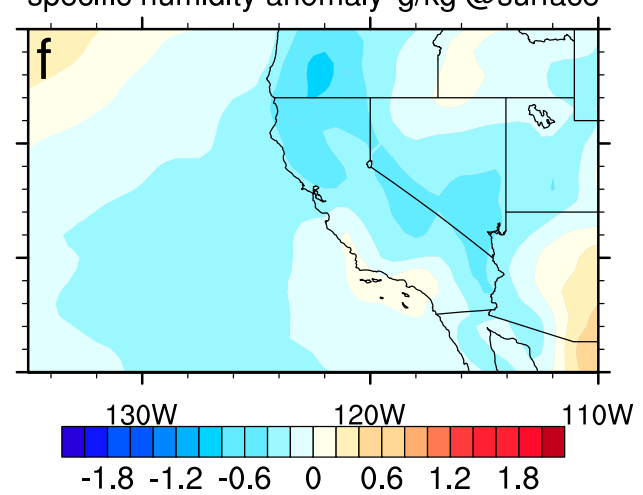

FIG. 11. As in Fig. 7, but for days in category 16 (the second-most frequent non-MAP category).

32) with the number of 1979-2010 MAP days then yields a corresponding probability of the day being a MAP day (i.e., category 1 is a MAP day $46 / 57=80.7 \%$ of the time and is not a MAP day $11 / 57=19.3 \%$ of the time). Summing the MAP probability over all days then gives the mean number of MAP days expected over that year. This procedure then allows us to understand how changes in the frequency of the 32 MAP categories will affect the frequency of MAP days.

Historical MAP days were selected in the CMIP5 datasets and VR-CESM dataset of Rhoades et al. (2016) using the five synoptic indicators, and we compared this selection with historical MAP days from CFSR. Figure 12 shows that the number of MAP days was found to vary around $42 \pm 4$ of the 92 days (JJA). In fact, there is surprisingly good agreement on the number of MAP days among all datasets (even though there was little agreement for a particular year), suggesting that there are no significant biases in the representation of the synoptic-scale meteorological pattern of this region.

Future trends in the five synoptic indicators in CMIP5 were then assessed under different climate scenarios, by 


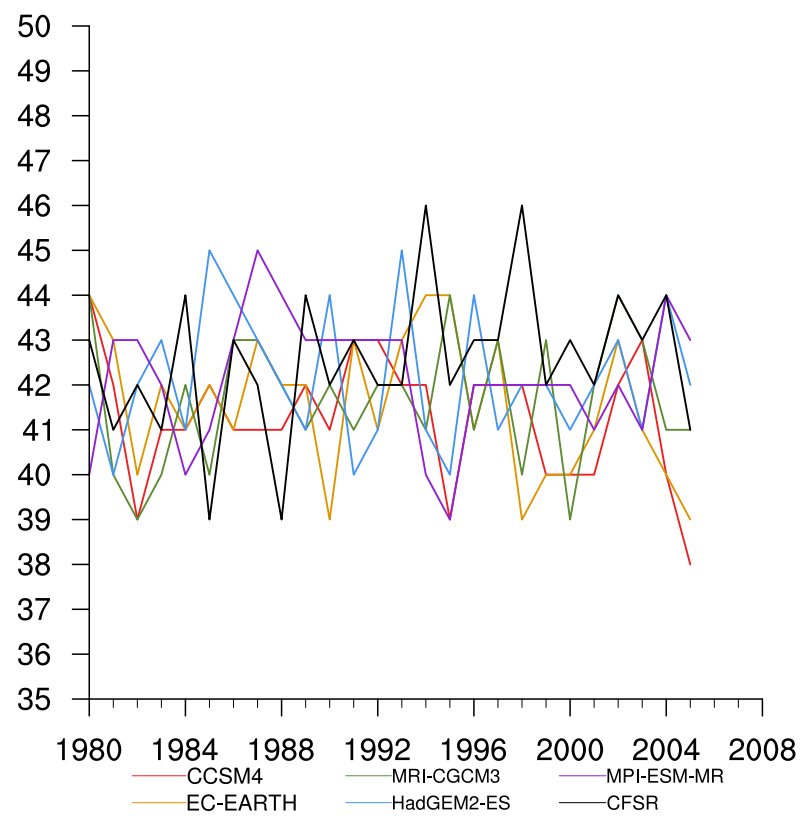

FIG. 12. Number of MAP days selected over JJA from CFSR and historical CMIP5 data.

analyzing experiments arising from the "business as usual" representative concentration pathway 8.5 (RCP8.5). Indicators 1,3 , and 5 were all anomalous values calculated from each year mean, and so this could include the annual variations during the study period. Therefore, building a linear regression line on the basis of the corresponding climatological field was necessary so that the climatological trends were better represented, and then the anomaly values for each indicator (1, 3, and 5) were calculated against the values from regression lines. As expected, all models exhibited enhanced inland temperatures and increases in geopotential height anomaly through the twenty-first century, consistent with the well-known consequences of climate change, but exhibited mixed behavior for the individual indicator fields. Nonetheless, as shown in Fig. 13, all datasets examined produced a small upward trend $\left[\sim 0.2\right.$ days $(100 \mathrm{yr})^{-1}$ on average]. The primary driver for enhanced MAP came from reduced alongshore wind speeds at $35^{\circ} \mathrm{N}, 125^{\circ} \mathrm{W}$ in all models, leading to more days that triggered indicator 5 , and this trend is consistent across all five CMIP5 models, although the magnitude varies. A slight reduction in geopotential height difference also emerged, which led to fewer days that triggered indicator 4 , although it was not enough to counteract the change in indicator 5 . There is no clear agreement between models for the geopotential ridging indicator 1 , the geopotential tendency indicator 2 , or the temperature indicator 3 . In summary, this result suggests that climate change may be weakly conducive to the emergence of synoptic-scale fields that are favorable to MAP. Nonetheless, we note that a key limitation of this study is that it cannot be used to draw conclusions on weaker MAP events or the effect of a cooler sea breeze (potentially associated with increased upwelling), both of which could also mitigate warming near the delta region.

\section{Conclusions}

The goals of this project have been threefold: first, to develop simple, objective criteria for the identification of MAP episodes in the California Central Valley from observational and reanalysis data; second, to characterize the synoptic- and large-scale meteorological fields that are correlated with these MAP episodes; and third, to bridge the gap between the relatively well understood future behavior of synoptic- and large-scale weather systems and a local-scale meteorological phenomenon. In this study, it was observed that MAP episodes could be identified as the conjunction of a temperature difference along the central valley and an onshore wind speed criterion. Using these criteria, MAP episodes were then associated with five large-scale indicators: 1) a positive geopotential anomaly in the Gulf of Alaska, 2) a negative geopotential tendency off the Oregon coast, 3) an inland surface temperature anomaly in the northwest part of the continental United States, 4) an offshore geopotential height difference, and 5) an offshore wind speed anomaly. These indicators then formed the foundation for a model for probabilistic prediction of MAP episodes. Last, by analyzing MAP events through the lens of synoptic-scale indicators, this study finds that climate change may favor synoptic-scale conditions that are conducive to MAP events.

We note that the connections across scales that emerge from this study can be further used for improving forecasts of MAP events using available synopticscale fields. We also argue that a similar method can likewise be employed to develop statistical relationships between large-scale fields and local meteorological features.

Many other factors play an important role in the emergence of MAP but were not investigated here, including local meteorological conditions, large-scale teleconnections, and coastal upwelling. In particular, coastal upwelling is theorized to intensify under climate change (Snyder et al. 2003) and has a strong influence on coastal temperatures and subsequently the strength of the cooling effect associated with MAP episodes. It also remains unclear how MAP interacts with other large-scale systems, such as the North Pacific Oscillation, Pacific decadal oscillation, and El Niño-Southern 


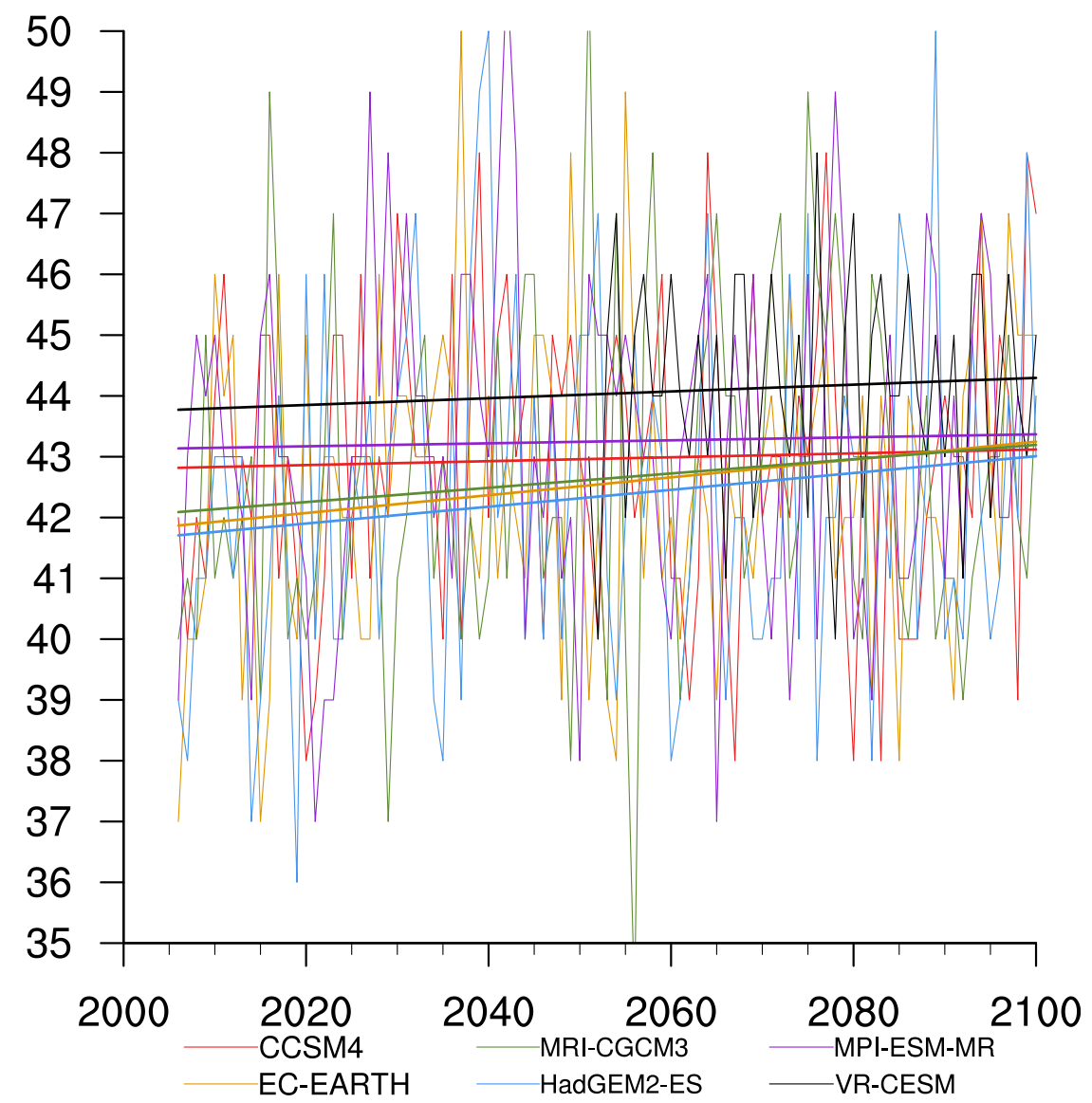

FIG. 13. Number of MAP days selected over each summer season from CMIP5 and VR-CESM under RCP8.5; the straight lines indicate the linear trends from each CMIP5 dataset.

Oscillation. Further, there is an incomplete understanding of how MAP interacts with other meteorological features, including coastal fog and tule fog. These topics remain for consideration in a future study.

Acknowledgments. The authors thank the University of California, Davis, Farm Cluster IT team (Bill Broadley, Terri Knight, and Curtis Combs) for their help and support with the computational resources throughout this project. Helpful and inspirational conversations with Dustin Grogan, Xue Meng Chen, and Alan Rhoades are much appreciated. We further thank the two anonymous reviewers for their thorough evaluation of the manuscript and suggested improvements. Funding for this work comes from the California Energy Commission EPIC program under Award EPC15-068. This material is also based upon work that is supported by the National Institute of Food and Agriculture, U.S. Department of Agriculture, hatch project under California Agricultural Experiment Station Project CA-D-LAW-2203-H.

\section{REFERENCES}

Beaver, S., and A. Palazoglu, 2006: Cluster analysis of hourly wind measurements to reveal synoptic regimes affecting air quality. J. Appl. Meteor. Climatol., 45, 1710-1726, doi:10.1175/ JAM2437.1.

Bellinder, A. L., 2012: The California delta breeze. Ph.D. dissertation, University of California, Davis, $141 \mathrm{pp}$.

Davis, T., D. Gaushell, D. Pierce, and M. Altalo, 2005: Guessing Mother Nature's next move. Public Util. Fortnightly, 143 (8), 48, https://www.fortnightly.com/fortnightly/2005/08/ guessing-mother-natures-next-move.

Fosberg, M. A., and M. J. Schroeder, 1966: Marine air penetration in central California. J. Appl. Meteor., 5, 573-589, doi:10.1175/ 1520-0450(1966)005<0573:MAPICC > 2.0.CO;2.

Grotjahn, R., and Coauthors, 2016: North American extreme temperature events and related large scale meteorological patterns: A review of statistical methods, dynamics, modeling, and trends. Climate Dyn., 46, 1151-1184, doi:10.1007/ s00382-015-2638-6.

Hsu, S.-A., 2013: Coastal Meteorology. Academic Press, 260 pp.

Huang, X., A. M. Rhoades, P. A. Ullrich, and C. M. Zarzycki, 2016: An evaluation of the variable-resolution CESM for modeling California's climate. J. Adv. Model. Earth Syst., 8, 345-369, doi:10.1002/2015MS000559. 
Lebassi, B., J. González, D. Fabris, E. Maurer, N. Miller, C. Milesi, P. Switzer, and R. Bornstein, 2009: Observed 1970-2005 cooling of summer daytime temperatures in coastal California. J. Climate, 22, 3558-3573, doi:10.1175/2008JCLI2111.1.

Mass, C. F., M. D. Albright, and D. J. Brees, 1986: The onshore surge of marine air into the Pacific Northwest: A coastal region of complex terrain. Mon. Wea. Rev., 114, 2602-2627, doi:10.1175/1520-0493(1986)114<2602:TOSOMA >2.0.CO;2.

Mayor, S. D., 2011: Observations of seven atmospheric density current fronts in Dixon, California. Mon. Wea. Rev., 139, 1338-1351, doi:10.1175/2010MWR3374.1.

Miller, S., B. Keim, R. Talbot, and H. Mao, 2003: Sea breeze: Structure, forecasting, and impacts. Rev. Geophys., 41, 1011, doi:10.1029/2003RG000124.

Olsson, L. E., W. P. Elliott, and S.-I. Hsu, 1973: Marine air penetration in western Oregon: An observational study. Mon. Wea. Rev., 101, 356-362, doi:10.1175/1520-0493(1973)101<0356: MAPIWO $>2.3$.CO;2.

Read, R. G., 1971: Marine air penetration of the Monterey Bay coastal strip and Salinas Valley, California. Moss Landing Marine Laboratories Tech. Publ. 71-2, 93 pp., http://islandora. $\mathrm{mlml}$.calstate.edu/islandora/object/islandora\%3A2367.

Rhoades, A. M., X. Huang, P. A. Ullrich, and C. M. Zarzycki, 2016: Characterizing Sierra Nevada snowpack using variable-resolution CESM. J. Appl. Meteor. Climatol., 55, 173-196, doi:10.1175/JAMC-D-15-0156.1.

Saha, S., and Coauthors, 2010: NCEP Climate Forecast System Reanalysis (CFSR) 6-hourly products, January 1979 to December 2010 (ds093.0). Research Data Archive at the National Center for Atmospheric Research, Computational and Information Systems Laboratory, accessed 24 Jan 2015, https://doi.org/10.5065/ D69K487J.

Schroeder, M., M. Fosberg, O. Cramer, and C. O. Dell, 1967: Marine air invasion of Pacific coast: A problem analysis. Bull. Amer. Meteor. Soc., 48, 802-808.

Simpson, J. E., 1994: Sea Breeze and Local Winds. Cambridge University Press, 234 pp.

Snyder, M. A., L. C. Sloan, N. S. Diffenbaugh, and J. L. Bell, 2003: Future climate change and upwelling in the California Current. Geophys. Res. Lett., 30, 1823, doi:10.1029/2003GL017647.

Snyder, R. L., 1984: California Irrigation Management Information System. Amer. J. Potato Res., 61, 229-234, doi:10.1007/BF02854009.

Taylor, K. E., R. J. Stouffer, and G. A. Meehl, 2012: An overview of CMIP5 and the experiment design. Bull. Amer. Meteor. Soc., 93, 485-498, doi:10.1175/BAMS-D-11-00094.1.

Zaremba, L. L., and J. J. Carroll, 1999: Summer wind flow regimes over the Sacramento Valley. J. Appl. Meteor., 38, 1463-1473, doi:10.1175/1520-0450(1999)038<1463:SWFROT>2.0.CO;2. 